\title{
The long non-coding RNA H19 suppresses carcinogenesis and chemoresistance in hepatocellular carcinoma
}

\author{
Christina S. Schultheiss ${ }^{1, \S}$, Stephan Laggai ${ }^{1, \S}$, Beate Czepukojc ${ }^{1}$, Usama K. Hussein ${ }^{1,2}$, Markus List ${ }^{3}$, Ahmad \\ Barghash ${ }^{4}$, Sascha Tierling ${ }^{5}$, Kevan Hosseini ${ }^{1}$, Nicole Golob-Schwarzl ${ }^{6}$, Juliane Pokorny ${ }^{7}$, Nina Hachenthal ${ }^{1}$, \\ Marcel Schulz ${ }^{3,9}$, Volkhard Helms ${ }^{10}$, Jörn Walter ${ }^{5}$, Vincent Zimmer ${ }^{8}$, Frank Lammert ${ }^{8}$, Rainer M. Bohle ${ }^{7}$, \\ Luisa Dandolo ${ }^{11}$, Johannes Haybaeck ${ }^{6,12}$, Alexandra K. Kiemer ${ }^{1, *}$, Sonja M. Kessler ${ }^{1,6}$ \\ ${ }^{1}$ Department of Pharmacy, Pharmaceutical Biology, Saarland University, Saarbrücken, Germany. \\ ${ }^{2}$ Faculty of Science, Beni-Suef University, Bani Suwaif, Egypt. \\ ${ }^{3}$ Department for Computational Biology and Applied Algorithmics, Max Planck Institute for Informatics, Saarland Informatics \\ Campus, Saarbrücken, Germany. \\ ${ }^{4}$ School of Electrical Engineering and Information Technology, German Jordanian University, Amman, Jordan. \\ ${ }^{5}$ Department of Genetics and Epigenetics, Saarland University, Saarbrücken, Germany. \\ ${ }^{6}$ Institute of Pathology, Medical University of Graz, Graz, Austria. \\ ${ }^{7}$ Institute of Pathology, Saarland University, Campus Homburg, Homburg (Saar), Germany. \\ ${ }^{8}$ Department of Medicine II, Saarland University Medical Center, Saarland University, Homburg (Saar), Germany. \\ ${ }^{9}$ Cluster of Excellence in Multimodal Computing and Interaction, Saarland Informatics Campus, Saarbrücken, Germany. \\ ${ }^{10}$ Center for Bioinformatics, Saarland University, Saarbrücken, Germany. \\ ${ }^{11}$ Institut Cochin, Inserm U1016, CNRS UMR 8104, Paris, France. \\ 12 Department of Pathology, Medical Faculty, Otto-von-Guericke University Magdeburg, Magdeburg, Germany. \\ ${ }^{\S}$ These authors contributed equally. \\ * Corresponding Author: \\ Alexandra K. Kiemer, Ph.D., Professor of Pharmaceutical Biology, Saarland University, Department of Pharmacy, Pharmaceutical \\ Biology, Campus C2 3, 66123 Saarbrücken, Germany; E-mail: pharm.bio.kiemer@mx.uni-saarland.de
}

ABSTRACT The long non-coding RNA (IncRNA) H19 represents a maternally expressed and epigenetically regulated imprinted gene product and is discussed to have either tumor-promoting or tumor-suppressive actions. Recently, H19 was shown to be regulated under inflammatory conditions. Therefore, aim of this study was to determine the function of $\mathrm{H} 19$ in hepatocellular carcinoma (HCC), an inflammation-associated type of tumor. In four different human HCC patient cohorts H19 was distinctly downregulated in tumor tissue compared to normal or nontumorous adjacent tissue. We therefore determined the action of $H 19$ in three different human hepatoma cell lines (HepG2, PIc/Prf5, and Huh7). Clonogenicity and proliferation assays showed that $\mathrm{H} 19$ overexpression could suppress tumor cell survival and proliferation after treatment with either sorafenib or doxorubicin, suggesting chemosensitizing actions of $\mathrm{H} 19$. Since HCC displays a highly chemoresistant tumor entity, cell lines resistant to doxorubicin or sorafenib were established. In all six chemoresistant cell lines $\mathrm{H} 19$ expression was significantly downregulated. The promoter methylation of the $\mathrm{H} 19$ gene was significantly different in chemoresistant cell lines compared to their sensitive counterparts. Chemoresistant cells were sensitized after $\mathrm{H} 19$ overexpression by either increasing the cytotoxic action of doxorubicin or decreasing cell proliferation upon sorafenib treatment. An $H 19$ knockout mouse model $(H 19 \Delta 3)$ showed increased tumor development and tumor cell proliferation after treatment with the carcinogen diethylnitrosamine (DEN) independent of the reciprocally imprinted insulin-like growth factor 2 (IGF2). In conclusion, $\mathrm{H} 19$ suppresses hepatocarcinogenesis, hepatoma cell growth, and HCC chemoresistance. Thus, mimicking $\mathrm{H} 19$ action might be a potential target to overcome chemoresistance in future HCC therapy. doi: $10.15698 /$ cst2017.10.105 Received originally: 03.04.2017; in revised form: 11.07.2017, Accepted 19.07.2017, Published 25.08.2017.

Keywords: loss of imprinting, miR675, Ki67, ELAVL1/HuR, flow cytometry, SNUPE, Bi-PROF.

\section{Abbreviations:}

$D E N$ - diethylnitrosamine, HCC - hepatocellular carcinoma, IGF-insulin-like growth factor, IncRNA - long non-coding RNA, LOI - loss of imprinting. 


\section{INTRODUCTION}

Non-coding sequences constitute the considerably larger part of the transcribed human genome compared to coding sequences since only $2 \%$ of the genome encode for proteins [1]

Recently, RNA-seq datasets were used to identify long non-coding RNAs (IncRNAs) aberrantly expressed under inflammatory conditions. The well-described IncRNA H19 (long intergenic non-protein coding RNA 8), a maternally expressed imprinted gene product, was the IncRNA with the most consistent overexpression among all conditions investigated [2]. Since cholangiocarcinoma represents a tumor type that develops under inflammatory conditions and in settings of oxidative stress, the authors investigated the role of $\mathrm{H} 19$ in cholangiocarcinoma cell lines and observed tumor-promoting and pro-inflammatory actions of
H19 [2], In contrast, H19 was found to have tumorsuppressing abilities in colorectal cancer, another inflammation-associated tumor entity [3], and the role of $H 19$ in inflammation is conflicting $[4,5]$. Embedded in $H 19$ 's first exon is the microRNA miR-675 [6], the processing of which is negatively regulated by the mRNA binding protein ELAV like RNA binding protein 1 (ELAVL1 / HuR) [7], and has also been reported to affect cancer [8] and inflammation [4, 5, $9,10]$.

Also hepatocellular carcinoma (HCC) evolves in an environment governed by metabolic and inflammatory stress as found in chronic viral hepatitis, as well as in alcoholic and non-alcoholic steatohepatitis [11]. HCC represents the second most common cause of cancer-related death worldwide [12], which is not least due to its high chemoresistance. However, the role of $\mathrm{H} 19$ in HCC development, progression, and chemoresistance is still unclear. While
A

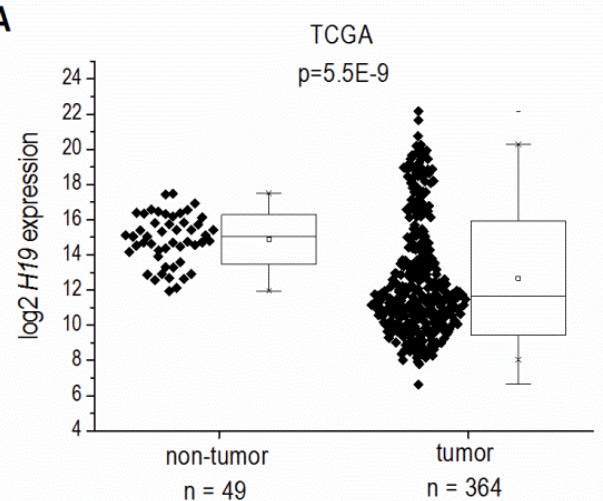

C



B

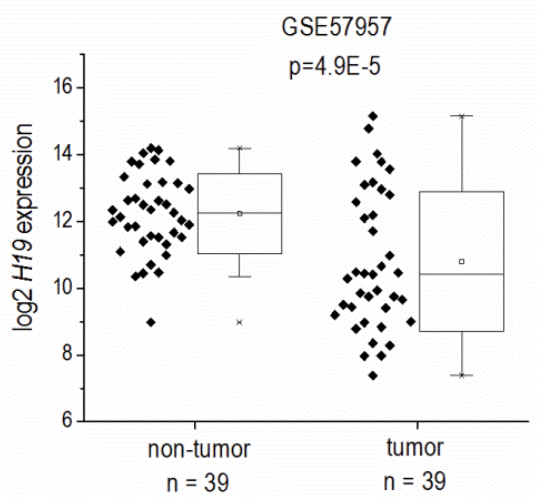

D

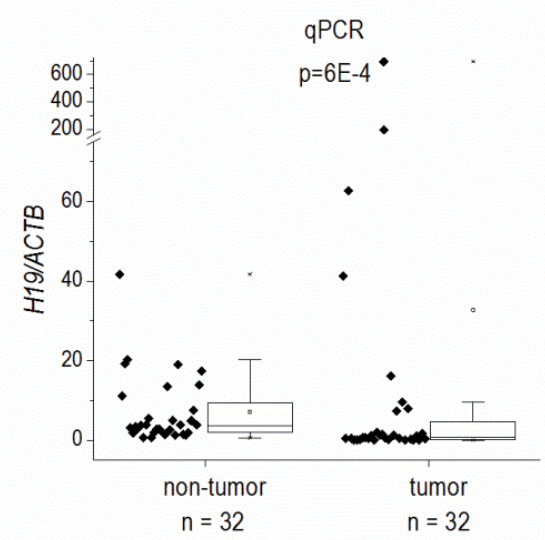

$\mathrm{CISH} / \mathrm{H} 19$

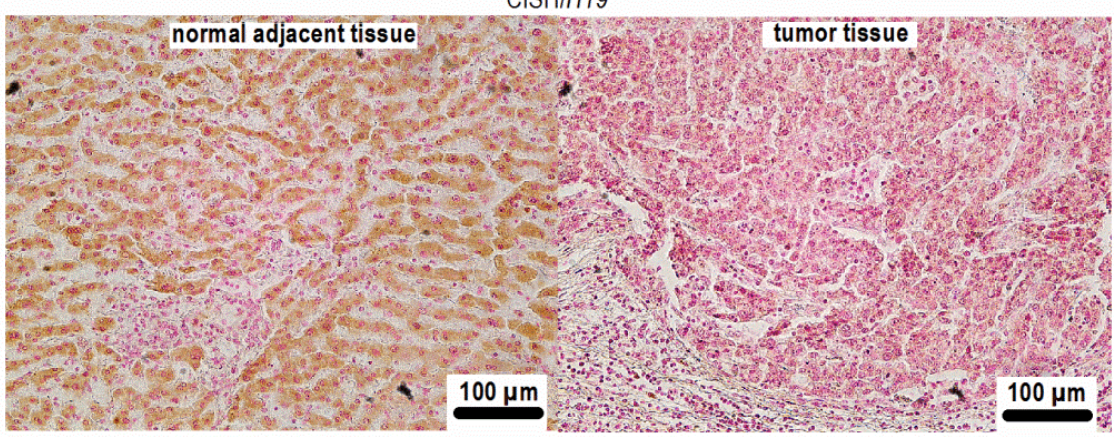

FIGURE 1: H19 expression in human HCC tissues (tumor) compared to non-tumorous tissues (non-tumor). (A) Log2 H19 expression in HCC tissues from TCGA dataset (non-tumor: $n=49$, tumor: $n=364$, MannWhitney $U$ test). (B) Log2 H19 expression in HCC tissues from GEO dataset GSE57957 (each, $\mathrm{n}=39$, Kolmo- gorovSmirnov test). (C) Log2 $\mathrm{H} 19$ expression in HCC tissues from GEO dataset GSE54236 (each, $\mathrm{n}=74, \quad$ KolmogorovSmirnov test). (D) H19 expression in HCC tissues from Saarland University Medical Center determined by qPCR (each, n=32, MannWhitney $U$ test). (E) Representative chromogenic in situ hybridization (CISH) of H19 (H19 positive cells: brown; H19 negative cells: red) (each, $n=8$ ). 
A

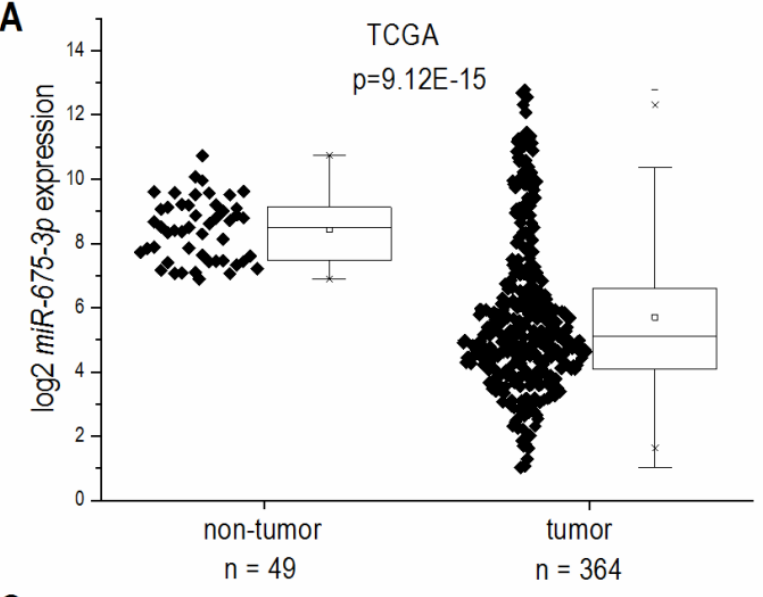

C

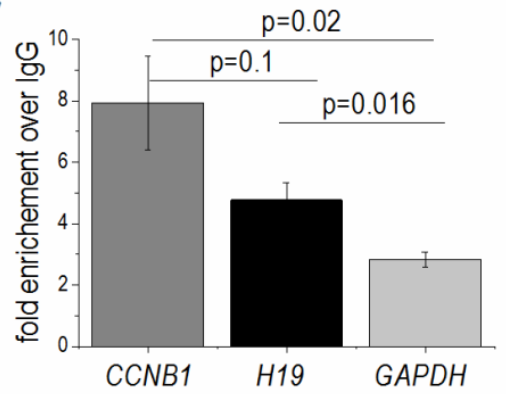

B

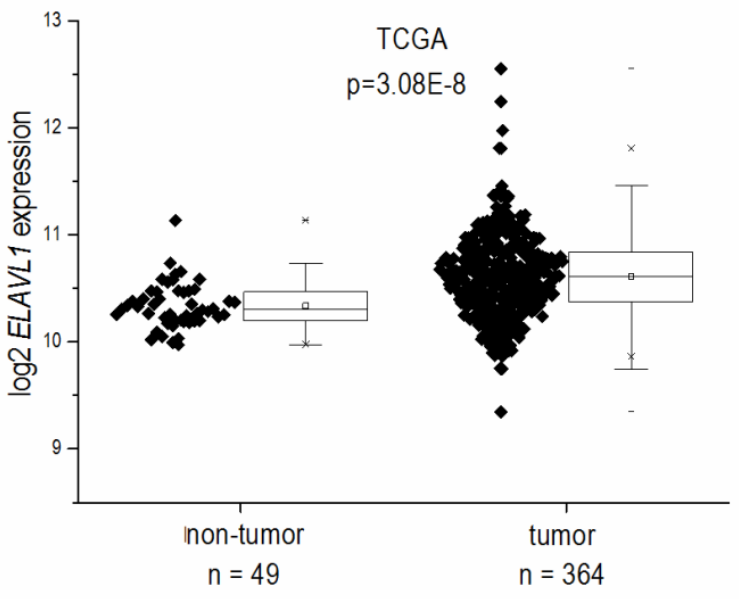

FIGURE 2: miR-675 and ELAVL1/HuR expression in human HCC tissues (tumor) compared to non-tumorous tissues (non-tumor). (A) Log2 miR675-3p expression and (B) Log2 ELAVL1 expression in HCC tissues from the TCGA dataset (non-tumor: $n=49$, tumor: $n=364$, Mann-Whitney $U$ test). (C) RIP was performed using either IgG or an HuR antibody. Co-precipitated mRNAs H19; CCNB1, as a positive control; GAPDH, as a negative control; were determined by qPCR ( $n=3$, duplicates). Data show $x$-fold enrichment over the levels found in IgG immunoprecipitates.

Yoshimizu et al. reported accelerated tumor development in H19 knockout mice in SV40-induced HCC [13], Matouk et al. observed an enhanced tumorigenic potential of carcinoma cells in vivo upon ectopic $H 19$ expression [14].

Allelic expression of $\mathrm{H} 19$ is controlled by an imprinting control region and by a promoter, which can be differentially methylated [15]. Loss of imprinting (LOI), i.e. biallelic H19 expression, was reported for HCC using small sample size cohorts [16, 17]. In general, human data on H19 expression in HCC should be interpreted with caution because the number of samples available for the studies dealing with this topic was mostly rather small $[16,17]$.

We therefore conducted comprehensive studies using four independent patient cohorts, $\mathrm{H} 19$ knockout mice, and three different human hepatoma cell lines to decipher the role of $H 19$ in HCC development, hepatoma cell growth, and chemoresistance.

\section{RESULTS}

Based on recent reports suggesting $\mathrm{H} 19$ as an inflammation-inducible IncRNA and HCC representing a disease developing in an inflammatory environment, we sought to determine $\mathrm{H} 19$ expression in human HCC. The comparison of $n=364$ HCC tissues with $n=49$ normal liver tissues from TCGA sequencing data revealed highest $H 19$ expression in a subgroup of HCC samples. Still, statistical analysis of all samples showed an allover decreased expression of $H 19$ in HCC tissue (Figure 1A). Comparing H19 expression of HCC tissues only to their respective adjacent tissues, H19 expression was still decreased with high statistical signifi- cance (data not shown, $p=5.28 E-7$ ). Also analysis of two microarray GEO datasets with $n=39 / 39$ (GSE57957) and $\mathrm{n}=74 / 74$ (GSE54236) HCC tissues vs. non-tumor tissue revealed a distinct downregulation of $H 19$ (Figure 1B and C) as did qPCR quantification of $H 19$ in a previously described patient cohort (Figure 1D) $[18,19]$. In situ hybridization against $H 19$ revealed low expression of $H 19$ in tumor tissue, but higher expression in the non-tumorous tissue adjacent to the tumor site in an additional patient cohort (Figure 1E). All cohorts comprised patients with HCC from different etiologies. q-PCR of hepatocytes, microdissected from the small subgroup of HCC samples showing high $H 19$ expression (Figure 1D) suggested that $H 19$ was in fact overexpressed in hepatocytes (Figure S2).

In accordance with the results from $\mathrm{H} 19$ expression, which encodes miR-675, the more abundant miR-675-3p was downregulated in HCC (Figure 2A) and strongly correlated with $H 19\left(R^{2}=0.91, p<1.0 E-15\right)$. The less of the abundant miR-675-5p was not detectable in most samples. The mRNA binding protein HuR/ELAVL1 has been shown to represent a negative regulator of $m i R-675$ processing in the mouse system by binding to $H 19$ [7]. Interestingly, expression of ELAVL1 was significantly upregulated in HCC (Figure 2B), suggesting an inhibited processing of $\mathrm{H} 19$ into miR675. RNA immunoprecipitation experiments in Huh7 cells confirmed that HuR/ELAVL1 also binds to human H19: H19 was significantly enriched in HuR immunoprecipitates over the negative control GAPDH (Figure 2C). Also the postive control CCNB1 showed a significantly enriched binding compared to the negative control. 
A

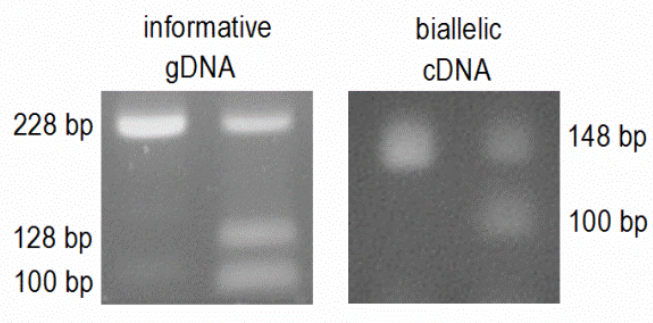

FIGURE 3: Epigenetic state of the $H 19$ locus in human HCC tissues (tumor) and non-tumorous tissues (nontumor). (A) LOI was analyzed by RFLP analysis of 9 informative gDNA samples. Representative agarose gel with gDNA and cDNA before (left) and after digestion with the restriction enzyme Alul (right). (B) H19 promoter methylation represented as fractional $\beta$ values from GEO dataset GSE57956 (each, $n=58$, Kolmogorov-Smirnov test).
B

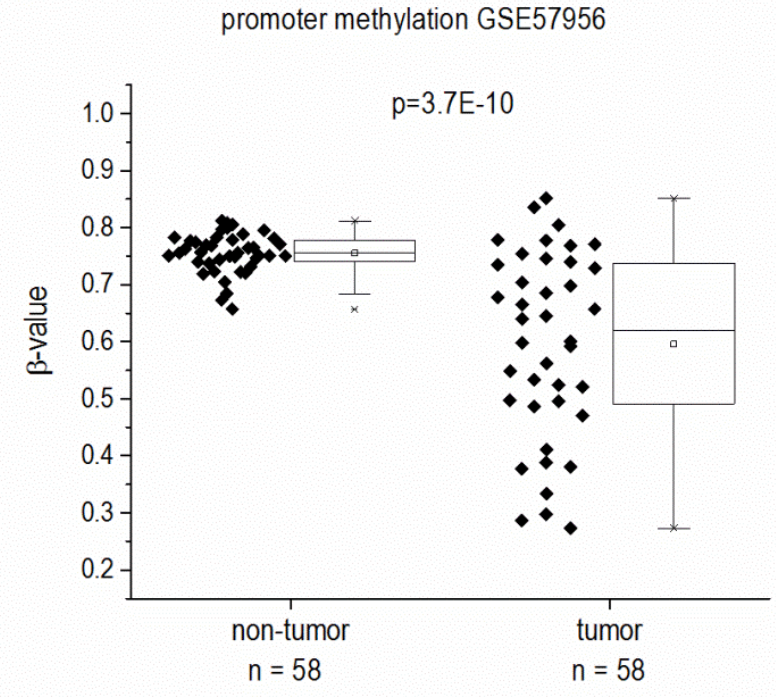

The data from independent patient cohorts showed a clear downregulation of $\mathrm{H} 19$ in HCC as a strongly inflammation-associated tumor type. This is why we investigated whether $\mathrm{H} 19$ expression is in fact downregulated due to an inflammatory reaction. In fact, we found a downregulation of $\mathrm{H} 19$ in livers from mice treated with the inflammationinducing carcinogen DEN $(n=5,0.11$ fold \pm 0.04 compared to untreated animals, $p=0.0508$, two-sample t-test).

Since $H 19$ 's expression is epigenetically controlled and LOI of $\mathrm{H} 19$ has been found in some tumor types, we determined allelic expression of $H 19$ in human HCC by RFLP analysis employing the 32 samples from our patient cohort (Figure 1D). The experiment showed that nine of the patients were heterozygous and therefore informative for RFLP analysis (Figure 3A). LOI was observed in three normal as well as in three tumor tissues while the other tissues showed monoallelic expression (Figure $\mathbf{3 A}$ ). These findings suggest that $\mathrm{LOI}$ is not involved in the deregulation of $\mathrm{H} 19$ expression in HCC.

Besides its regulation by imprinting mechanisms, $\mathrm{H} 19$ expression is also distinctly regulated by the extent of its promoter methylation $[20,21]$. Thus, we analyzed the HCC methylation dataset GSE57956 regarding H19 promoter methylation. This dataset also comprises the 39 samples, for which $\mathrm{H} 19$ expression was already determined (GSE57957, Figure 1B). The analysis revealed a distinctly decreased $\mathrm{H} 19$ promoter methylation with high statistical significance in HCC vs. normal tissues (Figure 3B).

Due to the downregulation of $H 19$ in $\mathrm{HCC}$ we aimed to determine functional aspects of $\mathrm{H} 19$ overexpression in liver cancer cells. Thus, the colony formation assay - a well established method to determine every cell's ability to undergo unlimited division in a cell population [22] - was performed in three different stably $\mathrm{H} 19$ overexpressing human hepatoma cell lines. All three cell lines we investigated, i.e. HepG2, Plc/Prf/5, and Huh7, showed that H19 suppresses tumor cell survival, as indicated by a reduced colony number (Figure 4A-D).

To explore the potential role of $H 19$ in chemosensitivity, the three stably $H 19$ overexpressing cell lines were treated with either sorafenib or doxorubicin, two therapeutics which have clinically been tested for HCC treatment [23, 24]. All stably $H 19$ overexpressing cell lines showed significantly increased sensitivity in the clonogenicity assay, suggesting a chemotherapy-sensitizing action of $\mathrm{H} 19$ (Figure 4A-D). In order to distinguish reduced colony formation from chemosensitizing actions of $H 19$, we also performed a different data normalization strategy, which can be found as supplemental Figure S3. Also this quantification confirmed a chemosensitizing action of $H 19$.

miR-675 is unlikely to be responsible for this action: while $H 19$ expression was significantly upregulated up to 65 -fold \pm 9.4 in stably transfected cells $(n=3$, triplicates, $p=2.4 E-6$, two-sample t-test), two of the three cell lines showed no increase in miR-675 expression $(n=3$, triplicates, each: HepG2: 9.2-fold \pm 7.3, $p=0.06$, Mann-Whitney $U$; Huh7: 1.7 -fold $\pm 1.0, p=0.36$, Mann-Whitney $U$ ). Only stably H19 overexpressing Plc/Prf/5 cells revealed slightly upregulated miR-675 expression ( $n=3$, triplicates, 1.5 -fold \pm 0.17 , $\mathrm{p}=1.2 \mathrm{E}-3$, two-sample t-test), while $\mathrm{H} 19$ was 6.9 -fold higher expressed ( $n=3$, triplicates, 10.3-fold $\pm 2.3, p=1 E-4)$. ELAVL1 mRNA levels were not affected in all three cell lines upon H19 overexpression (data not shown). In HepG2 and Huh7, the action was independent of the anti-apoptotic growth factor IGF2 [18], frequently regulated in parallel with $H 19$ due to the genomic vicinity and shared imprinting control region [25]: IGF2 expression was unchanged in both stably H19 overexpressing cell lines compared to empty vectortransfected controls ( $n=3$, triplicates each: HepG2: 1.4-fold $\pm 0.6, p=0.16$, Mann-Whitney $U$ test; Huh7: 1.1-fold \pm 0.1 , $\mathrm{p}=0.17$, two-sample t-test). Still, in Plc/Prf/5 the expression of IGF2 was significantly downregulated $(n=3$, triplicates, 
A

HepG2

$0.05 \mu \mathrm{g} / \mathrm{ml}$

co

H19

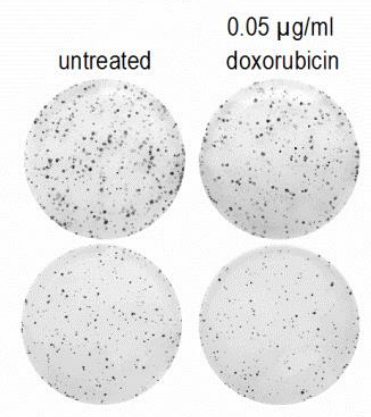

$\mathrm{Plc} / \mathrm{Pr} / 5$

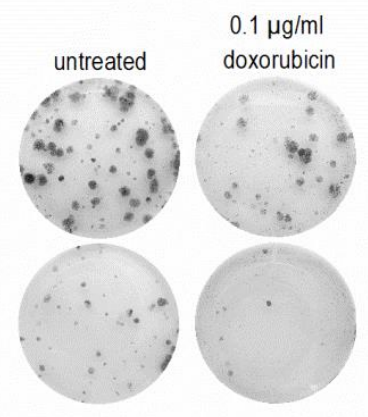

Huh7

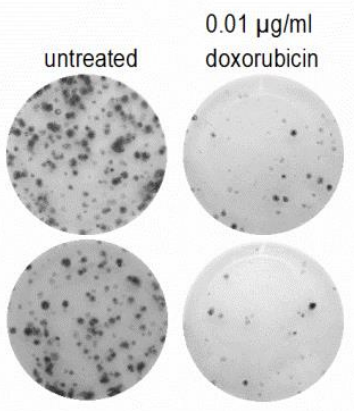

B

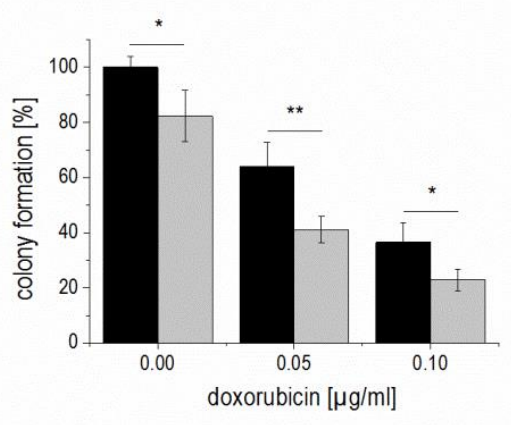

C

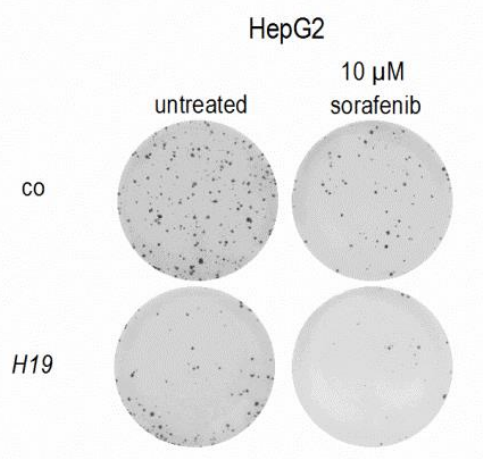

D

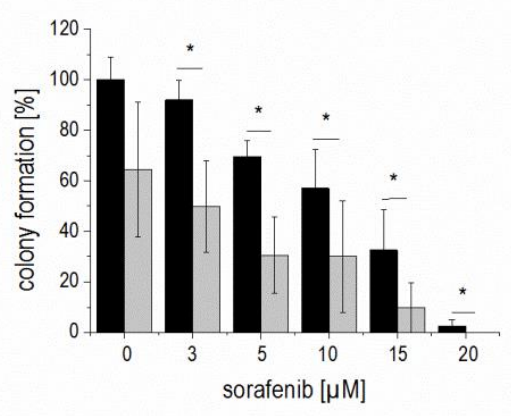

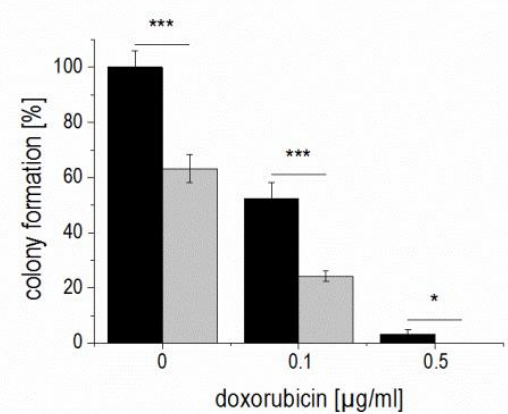

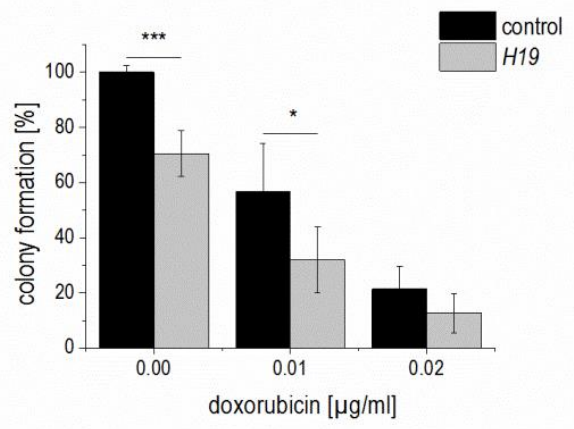

$\mathrm{Plc} / \mathrm{Pr} / 5$
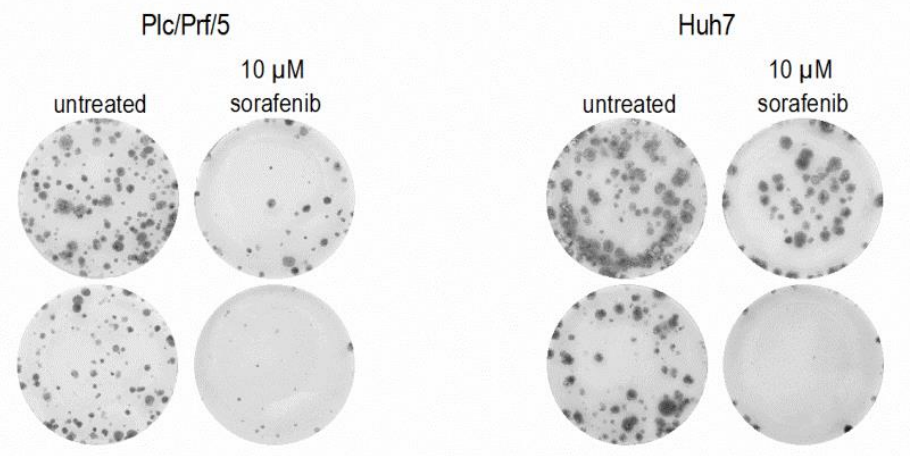

FIGURE 4: Effect of $H 19$ overexpression on colony formation ability in stably $H 19$ overexpressing $(H 19)$ and vector control (control, co) HepG2 (left panels), PIc/Prf/5 (middle panels), and Huh7 (right panels) cells. (A, C) Representative results of clonogenicity assays using untreated and (A) doxorubicin or (C) sorafenib treated hepatoma cells. (B, D) Colony formation ability of $H 19$ overexpressing cells normalized to their respective untreated control cells after (B) doxorubicin ( $\mathrm{n} \geq 3$, duplicates) or (D) sorafenib $(n=3$, triplicates) treatment. The $p$ values were calculated by two-sample $t$-test or Mann-Whitney $U$ test depending on the data distribution. ${ }^{*} p<0.05,{ }^{* *} p<0.01,{ }^{* * *} p<0.001$. 
0.3 -fold $\pm 0.1, p=3.9 E-6$, two-sample t-test). Interestingly, $\mathrm{Plc} / \mathrm{Prf} / 5$ exhibited a highly increased intrinsic chemoresistance compared to the other two cell lines.

In order to determine whether H19 overexpression or knockdown directly affected cytotoxicity, cell viability was measured by MTT assay either in stably H19 overexpressing cells or in cells with a gapmer-facilitated H19 knockdown upon treatment with the cytotoxic agent doxorubicin. Cell viability with overexpressed or knocked down $\mathrm{H} 19$ was largely unchanged in Plc/Prf/5 and Huh7 cells, although a few values reached statistical significance (Figure $\mathbf{5 A}$ and $\mathbf{B}$ ). Only in $\mathrm{H} 19$ gapmer-treated HepG2 cell viability was distinctly elevated compared to gapmer control cells (Figure 5B). These heterogenous findings suggested that H19facilitated chemosensitization in Plc/Prf/5 and Huh7 is unlikely to depend on altered cell death but might rather depend on reduced proliferative capacity.

Therefore, proliferation measurements in H19 overexpressing cells by Ki67 staining and subsequent FACS quantification were performed. Interestingly, while proliferation of HepG2 cells was unchanged in $H 19$ overexpressing cells, H19 exhibited a significant proliferation-suppressing activity in Plc/Prf/5 and Huh7 cells (Figure $\mathbf{5 C}$ ).

We hypothesized that a downregulation of $\mathrm{H} 19$ might also contribute to chemoresistance as induced by repeated treatment with chemotherapeutics. To test this hypothesis, we established doxorubicin- and sorafenib-resistant HepG2, $\mathrm{Plc} / \mathrm{Prf} / 5$, and Huh7 cell lines by repeated treatment with the drugs. Their chemoresistance was confirmed by directly comparing their sensitivity with non-resistant cells towards the drugs in a dose-response analysis (Figure 6A and B).

Quantifying $H 19$ expression by qPCR revealed that chemoresistance was associated with strongly downregulated $\mathrm{H} 19$ expression in doxorubicin resistant cells (Figure 6C). However, miR-675 was not significantly affected in any of the doxorubicin resistant cells $(n=2$, duplicates, each: HepG2-Dox-R: 0.52 -fold $\pm 0.30, p=0.11$, two-sample t-test; Plc/Prf/5-Dox-R: 0.71-fold $\pm 0.25, p=0.20$, two-sample ttest; Huh7-Dox-R: 2.13-fold $\pm 0.86 p=0.16$, two-sample ttest). Also in sorafenib resistant cell lines $H 19$ expression was significantly suppressed (Figure 6C).

Analysis of the multidrug resistance protein 1 (MDR1, $A B C B 1)$ showed increased expression in all doxorubicin $(n=2$, duplicates, each: HepG2-Dox-R: 44.2-fold \pm 8.8 , $\mathrm{p}=6.2 \mathrm{E}-3$, two-sample t-test; Plc/Prf/5-Dox-R: 1.8-fold \pm 0.2 , $p=3.1 E-2$, Mann Whitney $U$ test; Huh7-Dox-R: 6.7-fold \pm 0.4 $p=2.3 E-4$, two-sample t-test) and sorafenib resistant $(n=3$, triplicates, each: HepG2-Sora-R: 4.1-fold $\pm 0.7, p=4.5 \mathrm{E}-5$, two-sample t-test; Huh7-Sora-R: 1.5 -fold $\pm 0.2, p=3.4 \mathrm{E}-4$, two-sample t-test) cell lines except for sorafenib resistant Plc/Prf/5 cells ( $n=3$, triplicates, Plc/Prf/5-Sora-R: 0.6-fold \pm $0.1, p=2.8 \mathrm{E}-6$, two-sample t-test).

To elucidate if altered promoter methylation is again linked to changed $H 19$ expression, the $H 19$ promoter methylation status was analyzed by local deep bisulfite sequencing (Bi-PROF) covering $23 \mathrm{CpG}$ sites (Figure 7A) in the six chemoresistant cell lines. All three cell lines resistant for sorafenib showed elevated CpG methylation compared to their sensitive counterparts (Figure 7C): in Plc/Prf/5 cells 18 out of 23 investigated CpGs showed an elevated methylation; in HepG2 only 5 CpGs were hypermethylated (with 2 hypomethylated), while most CpGs were hypermethylated in Huh7 cells. Almost all investigated CpGs in Huh7 also showed an elevated methylation in doxorubicin resistance. Interestingly, though, almost half of the CpGs were hypomethylated in doxorubicin resistant $\mathrm{Plc} / \mathrm{Prf} / 5$ cells, and an almost equal number of $\mathrm{CpGs}$ was hyper- or hypomethylated in doxorubicin resistant HepG2 ( 3 up, 4 down) (Figure 7B). Taken together, although only Huh7 cells showed a consistent distinct hypermethylation, all three cell lines altered the methylation state of the $\mathrm{H} 19$ promoter during chemoresistance. Most differences were found at CpG sites close to the transcription start site of H19 (Figure 7A-C). Since these findings were highly reproducible in three independent biological replicates and similar to deregulated promoter methylation in HCC samples, we suggested an involvement of a deregulated promoter methylation in suppressed H19 expression during chemoresistance.

Therefore, we tested whether 5-azacytidine, a DNA demethylating agent, had an effect on chemosensitivity. As expected, the compound altered the $\mathrm{CpG}$ methylation of the $\mathrm{H} 19$ promoter in two of the three cell lines as measured by SNuPE (Figure $\mathbf{8 A}$ ) and significantly increased $\mathrm{H} 19$ expression in the same two cell lines (Figure 8B) with the strongest effect being seen in HepG2 cells, which were also distinctly sensitized towards doxorubicin in the presence of 5-azacytidine (Figure $\mathbf{8 C}$ ). This is why HepG2 cells were also employed for an approach to test whether H19 overexpression can reverse chemoresistance. We in fact observed an increased induction of cell death by doxorubicin after transfecting chemoresistant cells with H19 (Figure 8D). Since $H 19$ rather seemed to act on proliferative actions in Huh7, we overexpressed $\mathrm{H} 19$ in chemoresistant Huh7 cells and in fact also observed chemosensitization (Figure $8 \mathrm{E}$ ).

The data on reduced expression of $\mathrm{H} 19$ in human HCC and its chemosensitizing actions suggested tumorsuppressive actions of $\mathrm{H} 19$ in HCC. To determine whether the presence of $H 19$ has an impact on tumorigenesis, wildtype and $H 19$ knockout animals were treated with the carcinogen DEN for 24 weeks. As expected [26], male mice developed more tumors than female mice (Figure 9A). In both sexes, H19 knockout significantly increased the number of solid tumors. Trabecular tumors were only detectable in male $H 19$ knockout mice. The histological analysis also indicated that tumors of DEN-treated $\mathrm{H} 19$ deficient mice were characterized by small cell changes, representing dysplastic lesions found in the process of liver carcinogenesis (Figure 9B). 
A

HepG2



B

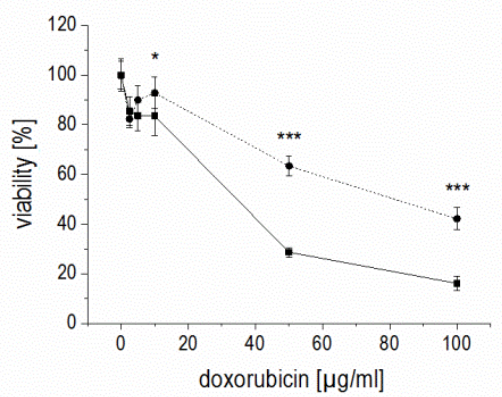

C
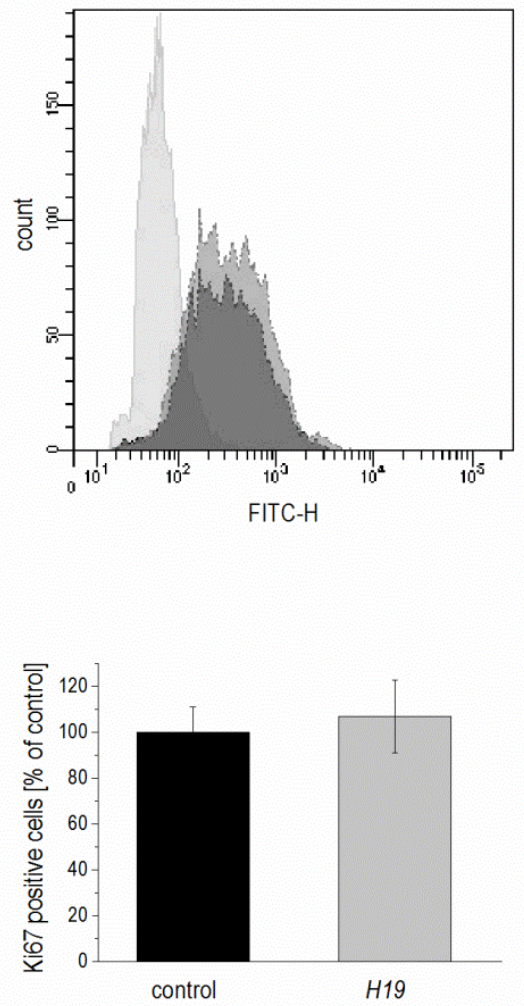

$\mathrm{Plc} / \mathrm{Prf} / 5$
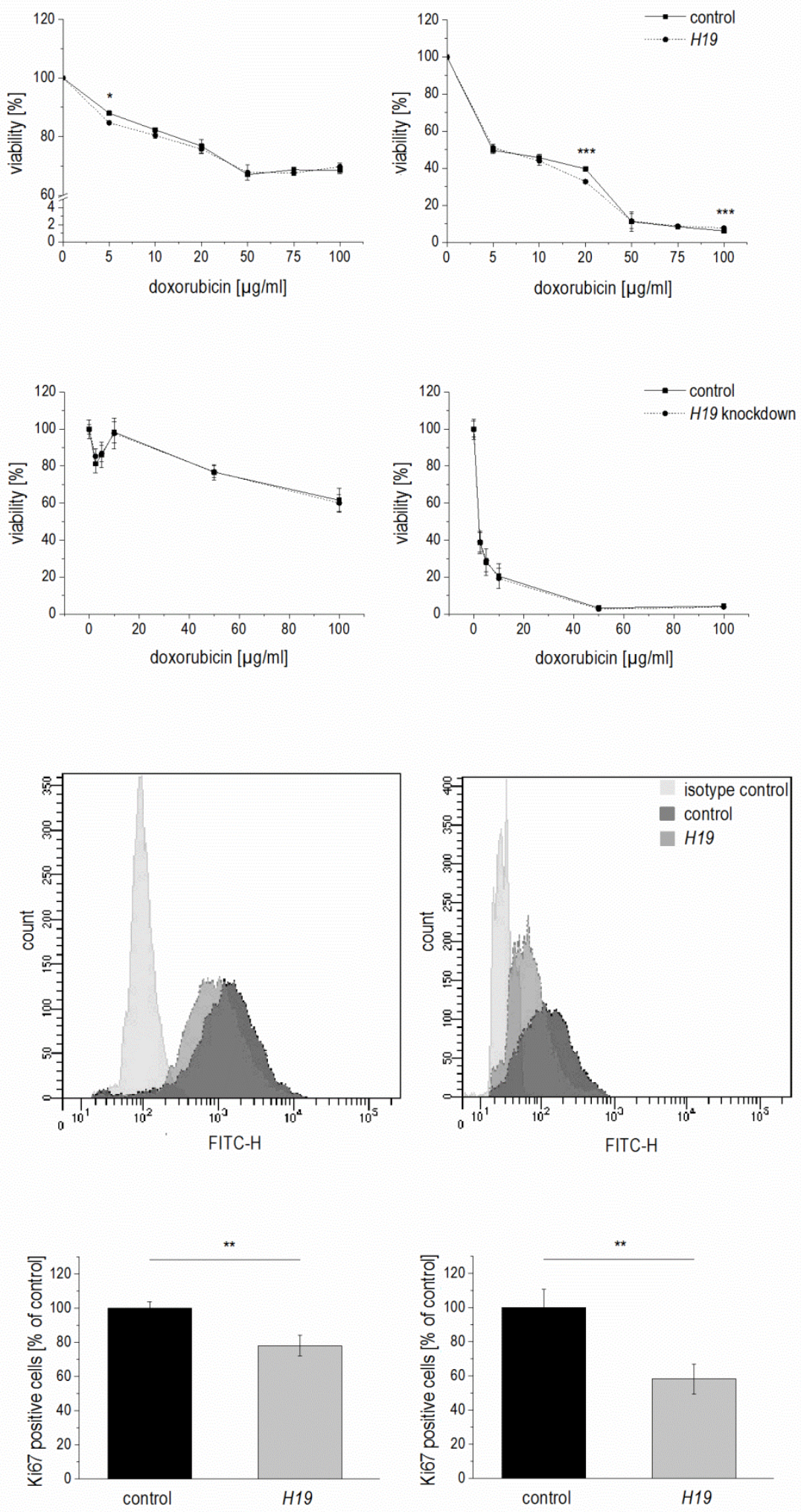

FIGURE 5: Effect of $H 19$ overexpression and knockdown on cell viability and proliferation in HepG2 (left panels), PIc/Prf/5 (middle panels), and Huh7 (right panels) cells. (A) Cytotoxicity assay with doxorubicin in stably $\mathrm{H} 19$ overexpressing (H19) or vector control (control) cells normalized to their respective untreated control ( $n=2$, sextuplicates). (B) Cytotoxicity assay with doxorubicin after transfection with H19 gapmer (H19 knockdown) and control gapmer (control) normalized to their respective untreated control ( $n=2$, sextuplicates). (C) FACS analysis of the proliferation marker Ki67 in stably H19 overexpressing (H19) and vector control cells (control). Representative histograms of Ki67 FACS analysis are shown (upper panels). Quantification of Ki67 positive cells expressed as percent of control ( $n \geq 2$, triplicates). The $p$ values were calculated by two-sample $t$-test or MannWhitney $U$ test depending on the data distribution. ${ }^{*} p<0.05,{ }^{* *} p<0.01, * * * p<0.001$. 
The proliferation-suppressive actions of $H 19$, as shown in the two human hepatoma cell lines Huh7 and Plc/Prf/5, could also be verified in vivo: $H 19$ deficient long-term DENtreated animals exhibited elevated Ki67 staining (Figure 9C). The expression of the oncogenic growth factor Igf2 was not different between wild-type and H19 knockout mice (Figure 9D), although Igf2 expression was significantly induced upon DEN treatment in $\mathrm{H} 19$ knockouts (Figure 9D).

\section{DISCUSSION}

H19 was first described more than thirty years ago, at a time when the biological role of non-coding RNAs was still undefined [27]. Since $H 19$ together with $\operatorname{lgf} 2$ and $\lg f 2 r$ belongs to the first imprinted genes described $[28,29]$, most of the first two decades of $H 19$ research focused on its epigenetic regulation.

While mouse data show a distinct downregulation of H19 expression in all tissues except for skeletal muscle after birth [28], analysis of human samples shows well detectable $\mathrm{H} 19$ levels in a wide array of tissue types (see e.g. http://medicalgenome.kribb.re.kr/GENT/). In fact, our analyses of four different patient cohorts comprising several hundreds of samples showed significantly higher $\mathrm{H} 19$ expression in normal liver tissue compared to HCC tissue. These findings support the findings of a previous study that analyzed $\mathrm{H} 19$ expression in $33 \mathrm{HCC}$ tissues by qPCR compared to either adjacent non-tumor tissue or remote relative normal tissue [30]. As in our results, some HCC tissues
A

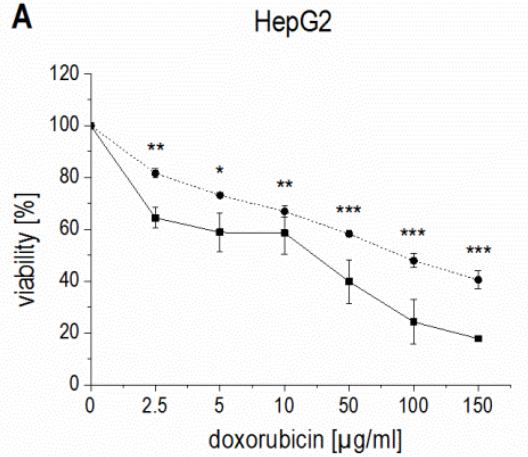

B

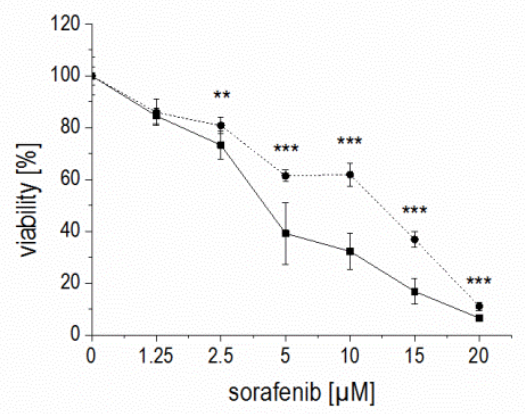

C

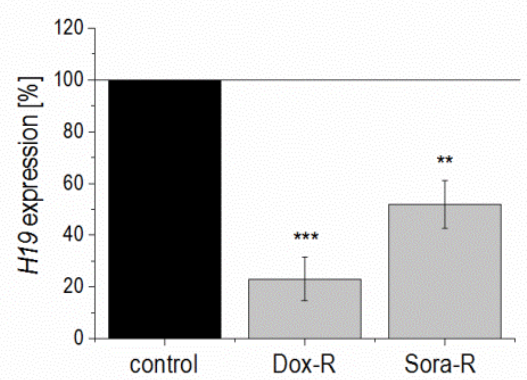

$\mathrm{Plc} / \mathrm{Prf} / 5$
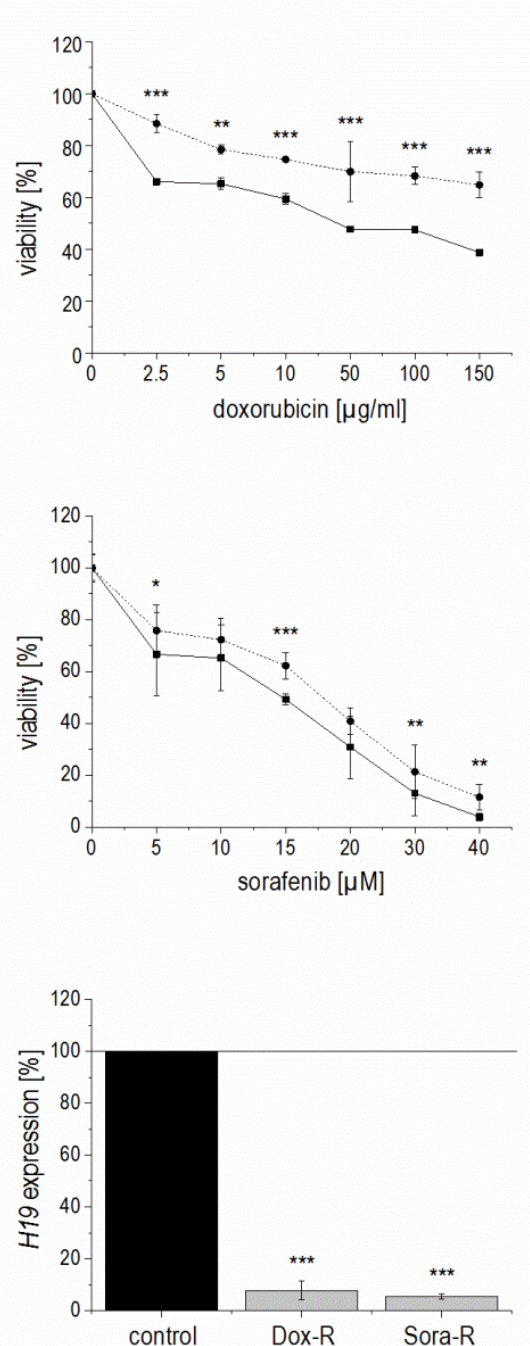
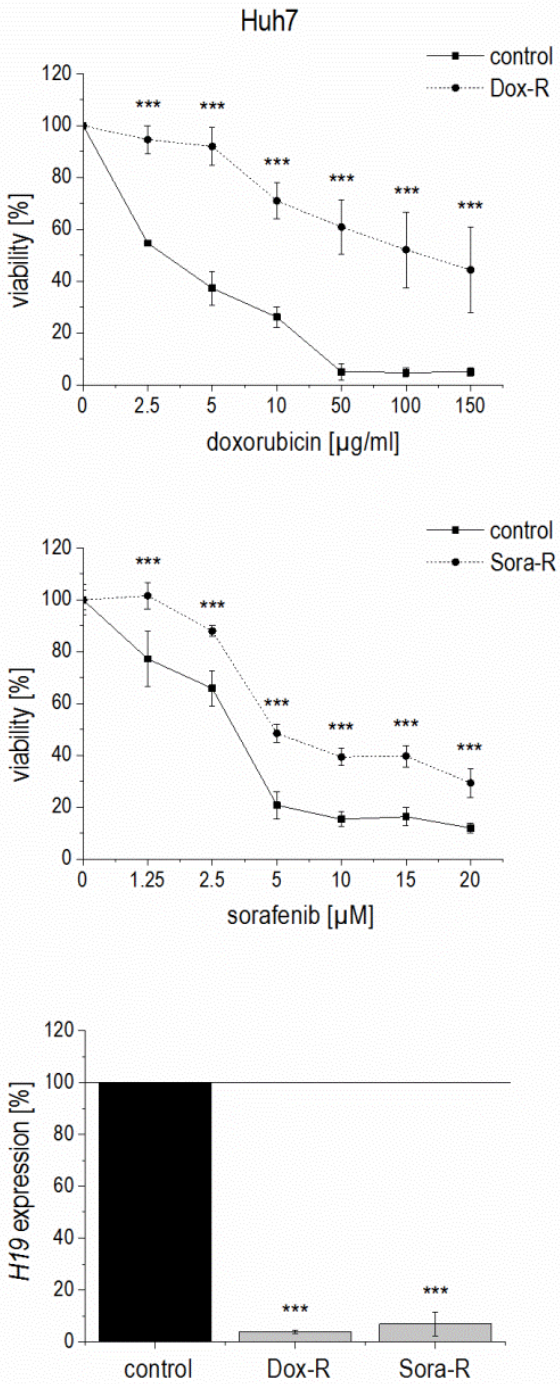

FIGURE 6: Validation of chemoresistance and expression of $H 19$ in sorafenib resistant (Sora-R), doxorubicin resistant (Dox-R), and chemosensitive (control) HepG2 (left panels), Plc/Prf/5 (middle panels), and Huh7 (right panels) cells. (A, B) Cytotoxicity assay normalized to the respective untreated control in (A) doxorubicin resistant cells ( $n=2$, quintuplicates) and (B) sorafenib resistant cells ( $n=3$, quintuplicates). (C) H19 expression determined by qPCR in doxorubicin ( $n=3$, duplicates) and sorafenib ( $n=3$, triplicates) resistant cells normalized to control cells. The $\mathrm{p}$ values were calculated by two-sample t-test or Mann-Whitney $U$ test depending on the data distribution. $* p<0.05, * * p<0.01$, $* * * \mathrm{p}<0.001$. 
of the latter study showed a dramatic increase in $\mathrm{H} 19$ expression, but alltogether $\mathrm{H} 19$ was downregulated in HCC with high statistical significance. In fact, H19 expression was significantly lower in invasive HCC samples $(n=31)$ compared to non-invasive HCC tumors $(n=41)$ [30].

Interestingly, other studies reported elevated $\mathrm{H} 19$ expression in HCC, e.g. [17, 31-33]. It has to be noted, however, that these studies investigated a considerably lower number of samples and/or used methods, such as in situ hybridization with limited quantitative reliability. Taking into account that all of our four patient cohorts, as well as those investigated by Zhang et al. (2013) [30], contained a small HCC patient subcohort with very high $H 19$ levels, it becomes clear that investigations of small patient cohorts can lead to contradictory findings.

Also reports on a potential loss of imprinting (LOI), i.e. biallelic $\mathrm{H} 19$ expression, are of limited significance. In fact, some studies have reported LOI in a subset of HCC tissues ranging between $21 \%$ and $66 \%$. The sample numbers of these studies, again, were very low $(n=3$ or $n=23)[16,17]$.

A

GGGTTTGGGAGAGTTTGTGAGGTCGTTTATCGTTTGTTAGTAGAGTGCGTTCGCGAGTCGTAAGTATAGTTCGGTAATAT GCGGTTTTTAGATAGGAAAGTGGTCGCGAATGGGATCGGGGTGTTTAGCGGTTGTGGGGATTTTGTTTTGCGGAAATCG CGGTGACGAGTATAAGTTCGGTTAATTGGATGGGAATCGGTTTGGGGGGTTGGTATCGCGTTTATTAGGGGGTTTGCGG TATTTTTTTTTGTTTTTTAGTATTTTATTTTTATTTTTTAGGAACGTGAGGTTTGAGTCGTGATGGTGGTAGGAAGGGGTTT $\rightarrow$ H19 transcription start site

B

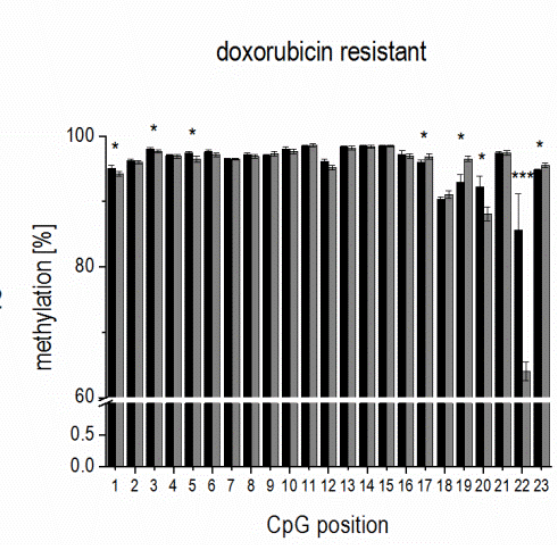

Plc/Prt/5


C
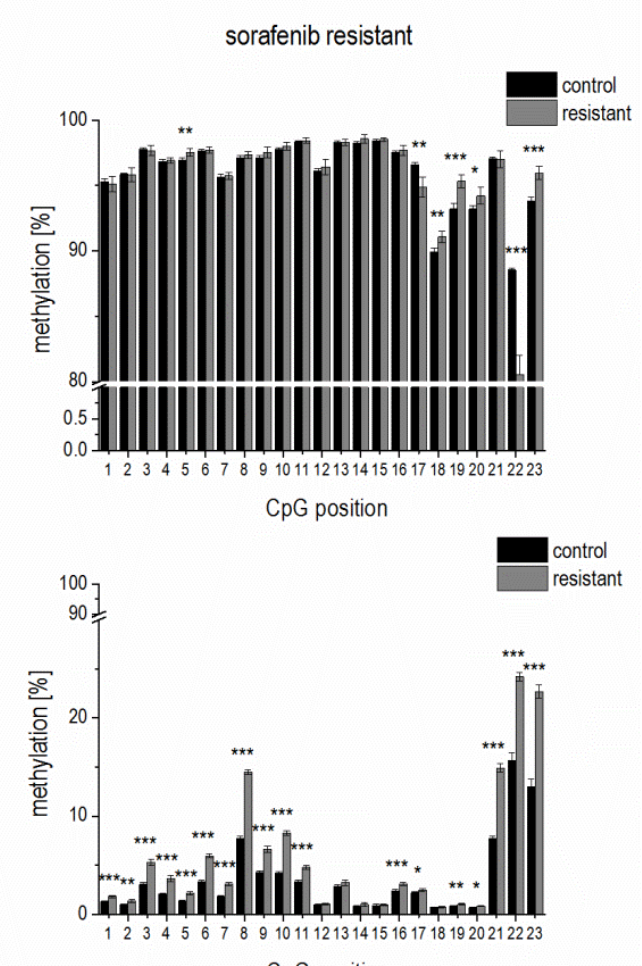

CpG position

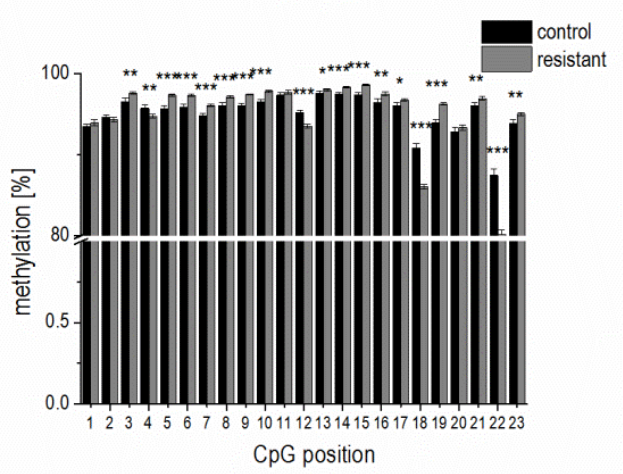

FIGURE 7: Methylation state of the H19 promoter in chemoresistant cells. (A) Analyzed $\mathrm{H} 19$ promoter region. The bisulphite-converted DNA sequence is shown; CpG sites 1-23 (Chr.11: 2,019,761 $2,019,488)$ are labelled in grey; amplification primers are underlined. (B, C) Absolute methylation of $23 \mathrm{CpG}$ sites located in the H19 promoter in chemoresistent (resistant) and chemosensitive (control) HepG2 (upper panels), Plc/Prf/5 (middle panels), and Huh7 (bottom panels) cells analyzed by $\mathrm{Bi}$ PROF $\quad(n=3, \quad$ triplicates). (B) Doxorubicin resistant and (C) sorafenib resistant hepatoma cells. The $p$ values were calculated by two-sample ttest or Mann-Whitney $U$ test depending on the data distribution. $* p<0.05, * * p<0.01$, $* * * p<0.001$. 
Our data revealed no difference in the imprinting status between normal and HCC tissue, with an equal proportion of samples exhibiting biallelic expression.

With the knowledge on a distinct regulation of $\mathrm{H} 19$ expression by epigenetic modifications, we focused on potential alterations in the methylation state of the $\mathrm{H} 19$ promoter. Indeed, we observed strongly altered $\mathrm{H} 19$ promoter methylation in human HCC vs. normal liver tissue. While decreased promoter methylation is typically thought to be linked to elevated gene expression [34-36], a hypermethylated promoter region has also been associated with increased expression of some genes [37, 38]. In fact, our data from a large HCC patient cohort suggested reduced promoter methylation correlating with reduced gene expression. Since HCC and other cancer types are associated with global DNA hypomethylation [39-41], the link between $\mathrm{H} 19$ expression and promoter methylation remains unclear, and should be clarified in further studies. We observed the same in the investigated doxorubicin resistant $\mathrm{Plc} / \mathrm{Prf} / 5$ cell line, which showed both reduced $\mathrm{H} 19$ expression and reduced promoter methylation compared to its chemosensitive counterpart. Interestingly, Plc/Prf/5 showed a much lower baseline promoter methylation compared to both HepG2 and Huh7, suggesting a differential epigenetic profile. Along this line, treatment of Plc/Prf/5 cells with the DNA demethylating agent 5-azacytidine neither affected H19 promoter methylation nor H19 expression.

All three sorafenib resistant cell lines as well as doxorubicin resistant Huh7 cells exhibited significantly elevated H19 promoter methylation and at the same time significantly reduced $\mathrm{H} 19$ expression compared to their respective chemosensitive counterparts. These findings are in line with anti-correlated methylation of the $\mathrm{H} 19$ promoter and expression of $H 19$ as found by others [20, 21]. Accordingly, treatment with the methyltransferase inhibitor 5azacytidine reduced $H 19$ promoter methylation in both HepG2 and Huh7 cells and significantly increased H19 expression, as previously observed in other cell types [42]. Interestingly, $\mathrm{H} 19$ itself has been reported to increase DNMT3B-mediated cytosine methylation [43], suggesting diverse feedback processes.

Induction of $\mathrm{H} 19$ by 5 -azacytidine in HepG2 and Huh7 cells increased their chemosensitivity. This confirms findings in the literature on chemosensitizing actions of the compound [44]. Chemoresistant versions of all three investigated cell lines showed downregulated $H 19$ expression. This suggested chemosensitizing actions of H19. In fact, H19 overexpression sensitized all three tested cell lines against both sorafenib and doxorubicin in clonogenicity assays. This effect seems to result from a synergistic effect of H19's antiproliferative and chemosensitizing actions. These findings on chemosensitizing action of $\mathrm{H} 19$ are in contrast to a paper reporting chemoresistance induction by $\mathrm{H} 19$ and linking it to induction of the multidrug resistance protein (MDR1, ABCB1) [45]. Our investigations employing three different hepatoma cell lines could not verify these effects.

Chemosensitizing actions of $\mathrm{H} 19$ in our hands seemed to differ between the different cell lines: in HepG2 cells, modulation of $\mathrm{H} 19$ expression rather affected cell death, whereas in Huh7 cells, $H 19$ suppressed proliferation.

Our clonogenicity data suggest growth-suppressive actions of $\mathrm{H} 19$ in the absence of any drug treatment. These data corroborate a hypothesis on the role of maternally expressed genes in embryonic development, already formulated in the early 1990s [46]. It provided a model of parental conflict, in which the females, through maternally expressed genes, balance resources allocated to current and future offspring. This notion led to the anticipation that maternally expressed genes limit growth.

Our in vivo data employing $\mathrm{H} 19$ knockout mice showed accelerated tumor development and more aggressive tumors. The literature contains two different $H 19$ knockout mouse models. One of them, the $H 19 \Delta 13$ mouse, shows a distinct overgrowth phenotype [47]. This overgrowth is facilitated by a full re-expression of the adjacent lgf2 gene from the normally silent maternal allele due to the combined $13 \mathrm{~kb}$ deletion of the $\mathrm{H} 19$ gene and of the imprinting control region [47]. In the $H 19 \Delta 3$ knockout model, which we used and which only carries a $3 \mathrm{~kb}$ deletion of the $\mathrm{H} 19$ gene, only a slight re-expression of the maternal lgf2 was detected in mesodermal tissue [48]. With liver representing an endodermal tissue, lgf2 expression is not increased in $H 19 \Delta 3$ mice as previously reported [48] and confirmed by ourselves.

In contrast to our findings Matouk et al. (2007) [14] suggested tumor promoting actions of $H 19$ in a xenograft model employing Hep3B cells. Different aspects might be responsible for this discrepancy. While our model involves in vivo tumor induction, a xenograft model employs established tumor cells. So tumor-inducing actions cannot be investigated with a xenograft model. Another aspect relates to the role of the immune defense, since tumor growth and development are strongly controlled by the immune system and xenograft models employ immune deficient mice. In 2008, Yoshimizu and colleagues investigated the role of $\mathrm{H} 19$ and reported in fact that in vivo $\mathrm{HCC}$ development was accelerated in $\mathrm{H} 19$ knockout mice [13].

There are several papers that regard $H 19$ as a promoter of cancer initiation and progression in a set of tumor types [8]. Interestingly, most of the $\mathrm{H} 19$ actions in this context have been explained by miR-675, a microRNA embedded within $H 19$. This microRNA targets a whole array of transcripts, such as Igf1r, Smad1, Smad5, Cdc6, CDH-11 and -13, RB1, RUNX1, NOMO1, TGFBI, CALN1, and MITF (reviewed in [8]) and promotes cell proliferation [49]. In contrast, a recently published paper clearly showed that $H 19$ reduces proliferation [50].

Taken together, the discrepancy of effects of $H 19$ in the three different cell lines and the controversial literature data suggest a strong context dependency, and needs to be addressed in further studies.

While the expression of $\mathrm{H} 19$ was always strongly affected in our chemoresistance and proliferation studies, miR-675 showed minimal expression alterations. This is why we assume that in HCC it is rather $\mathrm{H} 19$ than miR-675, 
HepG2


B
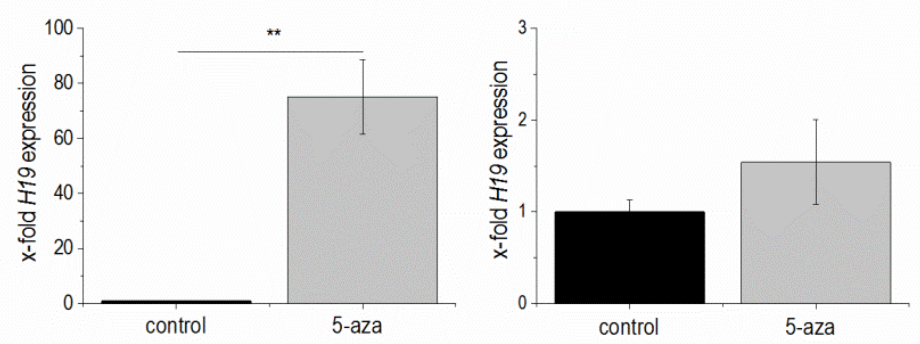

C
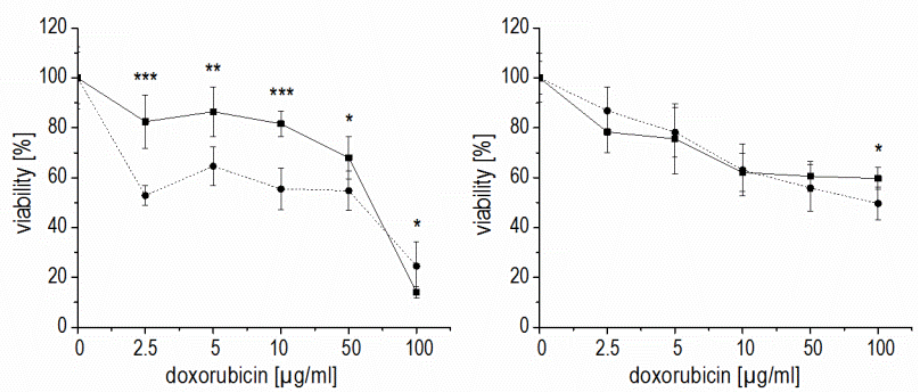

Huh7
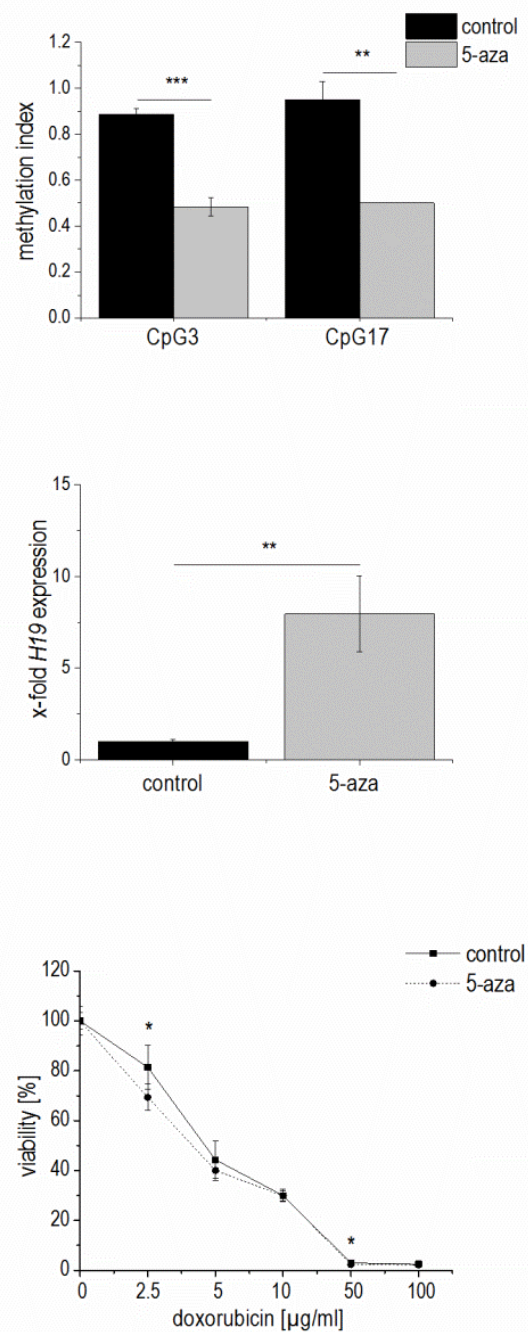

D

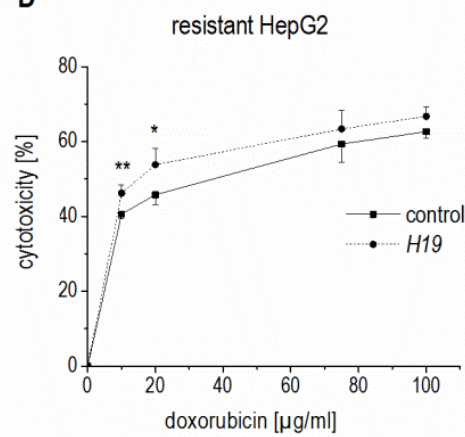

E

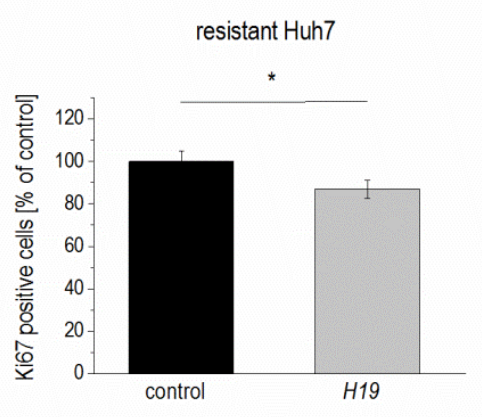

FIGURE 8: Methylation dependent $\boldsymbol{H} 19$ expression and its effect on cell viability and proliferation. (A-C) HepG2 (left panel), Plc/Prf/5 (middle panel), and Huh7 cells (right panel) treated with 5-azacytidine (5-aza) and untreated control cells (control) were analyzed for (A) methylation index of two CpG sites of the $H 19$ promoter by SNUPE ( $n=2$, duplicates), (B) H19 expression determined by qPCR ( $n=2$, duplicates), and (C) viability after treatment with doxorubicin by cytotoxicity assay ( $n=2$, quintuplicates). (D) Cytotoxicity estimated by MTT assay after treatment with doxorubicin in doxorubicin resistant HepG2 either transiently overexpressing $H 19$ (H19) or vector control transfected (control) for $48 \mathrm{~h}$ normalized to the respective untreated control ( $\mathrm{n}=2$, triplicates). (E) Quantification of Ki67 positive cells by FACS in sorafenib resistant Huh7 either transiently overexpressing $\mathrm{H} 19$ (H19) or vector control transfected (control) for $48 \mathrm{~h}$ and expressed as percent of control (each, $n \geq 2$, duplicates). The $p$ values were calculated by two-sample t-test or Mann-Whitney $U$ test depending on the data distribution. ${ }^{*} \mathrm{p}<0.05, * * \mathrm{p}<0.01, * * * \mathrm{p}<0.001$. 
which exerts biological actions. Interestingly, the mRNA binding protein HuR/ELAVL1, which has immunoregulatory potential (e.g. [51]) and suppresses the processing of $H 19$ into miR-675 [7], is overexpressed in human $\operatorname{HCC}[52,53]$, but not differentially expressed in our chemoresistant cell lines. In fact, tumor-promoting actions by HuR/ELAVL1 via the inhibition of microRNA processing in HCC have recently been reported [54].

Taken together, despite a small patient subcohort showing overexpressed $\mathrm{H} 19$, the majority of HCC tissues contained significantly reduced levels of this epigenetically regulated IncRNA. With its effect on HCC cancer cell growth, chemosensitivity, and carcinogenesis, H19 shows tumor-suppressive actions. Restoring $\mathrm{H} 19$ actions might therefore represent an interesting approach for future HCC therapy.

\section{MATERIALS AND METHODS \\ Bioinformatic analyses \\ TCGA data}

RNAseq expression data were obtained from The Cancer Genome Atlas (https://cancergenome.nih.gov) via the Genomic Data Commons (https://gdc.cancer.gov), using the TCGAbiolinks R package (v.2.2.6) [55]. The dataset comprised 364 primary solid tumor as well as 49 matched healthy liver tissue samples. For gene expression analysis, RSEM [56] normalized read counts were downloaded and log2-transformed.

\section{GEO datasets}

For differential gene expression analyses, 39 tumor and 39 adjacent non-tumor samples from the Total RNA Illumina HumanHT-12 V4.0 dataset GSE57957 were included. Similarly, differential gene expression was analyzed in dataset GSE54236 between tumor $(n=74)$ and non-tumor $(n=74)$ samples of an Agilent-014850 Whole Human Genome Microarray 4x44K G4112F (three samples without sufficient information per group were excluded). Additionally, the methylation of the H19 promoter region $2 \mathrm{~kb}$ around the transcription start site was analyzed using the GSE57956 dataset of bisulfite converted DNA from 58 tumors and 58 adjacent non-tumor samples hybridized to an Illumina Infinium 27k Human Methylation Beadchip (two samples without sufficient information per group were excluded). A subset of samples from GSE57956 was equal to the expression dataset GSE57957.

\section{Clinical samples}

32 human paraffin-embedded liver samples of tumor and matched non-tumorous adjacent tissue from randomly selected pseudonymized HCC patients who underwent liver resection at the Saarland University Medical Center between 2005 and 2010 were obtained [18]. The study protocol was approved by the local Ethics Committee (Kenn-Nr. 47/07). Clinical data were described previously $[18,19]$.

\section{Microdissection and RT-PCR}

Tissue sections of paraffin-embedded (FFPE) tissues were mounted on nuclease and human nucleic acid free glass MembraneSlides (Leica Microsystems CMS, Wetzlar, Germany, order no. 11505189), deparaffinized and stained with haemalaun. Laser microdissection was performed as described previously $[57,58]$ using a Leica LMD6000 microscope (Leica
Microsystems CMS). Laser-microdissected cells were transferred into a reaction tube containing PKD buffer (Qiagen, Germany). RNA was isolated according to manufacturer's protocol "Purification of total RNA from microdissected FFPE tissue sections" using the RNeasy FFPE Kit (Qiagen, Hilden, Germany). 28 ng RNA were reverse transcribed using random primers as described [18].

\section{RNA isolation and quantitative real-time RT-PCR (qPCR)}

Isolation of total RNA with QIAzol lysis reagent (Qiagen, Hilden, Germany), DNase digestion, reverse transcription of $0.5 \mu \mathrm{g}$ RNA, and real-time RT-PCR were performed as described previously [59--62]. For microRNAs the procedure was performed accordingly with minor modifications: the RNA after isopropanol precipitation was not washed with ethanol and reverse transcription with $2 \mu \mathrm{g}$ RNA was performed using the miScript II RT Kit and HiSpec Buffer (Qiagen, Hilden, Germany) as recommended by the manufacturer. Samples along with plasmid standard dilution series from 80 to 0.00008 attomol were run in triplicates using 5xHOT FIREPolTM Evagreen ${ }^{\circledR}$ qPCR Mix Plus (Solis BioDyne, Tartu, Estonia) in a CFX96 cycler (Bio-Rad, Munich, Germany) with specific primers (Table S1) (Eurofins Genomics, Ebersberg, Germany). The reaction conditions for the detection of mRNAs were $95^{\circ} \mathrm{C}$ for $15 \mathrm{~min}$ followed by 40 cycles of $30 \mathrm{~s}$ at $94^{\circ} \mathrm{C}, 30 \mathrm{~s}$ at primer-specific annealing temperature (AT listed in Table S1), and $30 \mathrm{~s}$ at $72^{\circ} \mathrm{C}$. A melting curve from $55^{\circ} \mathrm{C}$ to $95^{\circ} \mathrm{C}$ was recorded to detect potential unintended products. For the detection of microRNAs the reaction conditions were $95^{\circ} \mathrm{C}$ for $15 \mathrm{~min}$, followed by $40 \mathrm{cy}$ cles of $15 \mathrm{~s}$ at $94^{\circ} \mathrm{C}, 30 \mathrm{~s}$ at primer-specific annealing temperature (AT listed in Table S1), and $30 \mathrm{~s}$ at $70^{\circ} \mathrm{C}$. The human gene expression samples were normalized to actin beta (ACTB); murine samples to casein kinase 2 alpha 2 (Csnk2a2), and microRNAs were normalized to RNU6B.

\section{H19 RNA immunoprecipitation}

Immunoprecipitation (IP) of HuR-associated RNAs from Huh7 cells, validation of IP by western blot, and qPCR for the negative control GAPDH and the positive control cyclin B1 were performed as described previously [51]. Primer sequences and conditions for H19 IP qPCR (H19 IP) can be found in supplemental Table S1.

\section{RFLP (restriction fragment length polymorphism) analysis} Genomic DNA (gDNA) was isolated from paraffin-embedded tissues using the QIAamp DNA FFPE Tissue Kit (Qiagen, Hilden, Germany) according to the manufacturer's instructions. Genomic DNA was amplified to screen liver tissue samples for heterozygosity at a known Alul polymorphism at the $\mathrm{H} 19$ gene [63]. 9 of the 32 samples [18] were heterozygous and therefore corresponding CDNA was tested for biallelic expression. Primer sequences used were the following: 5' TACAACCACTGCACTACCTG-3' (sense), 5' TGGCCATGAAGATGGAGTCG-3' (antisense). The PCR reaction was performed using the DyNAmo Flash SYBR ${ }^{\circledR}$ Green Master mix containing $400 \mathrm{nM}$ primer, each. Amplification was performed in a Thermal Cycler (Px2 Thermal Cycler, Thermo Electron Corporation, Schwerte, Germany). PCR products were digested for $2 \mathrm{~h}$ at $37^{\circ} \mathrm{C}$ with Alul (Fermentas, St. Leon-Rot, Germany). Detection of existence of polymorphisms and expression status was done by agarose gel electrophoresis showing three bands (228 bp, $128 \mathrm{bp}$, and $100 \mathrm{bp}$ ) in gDNA 
A

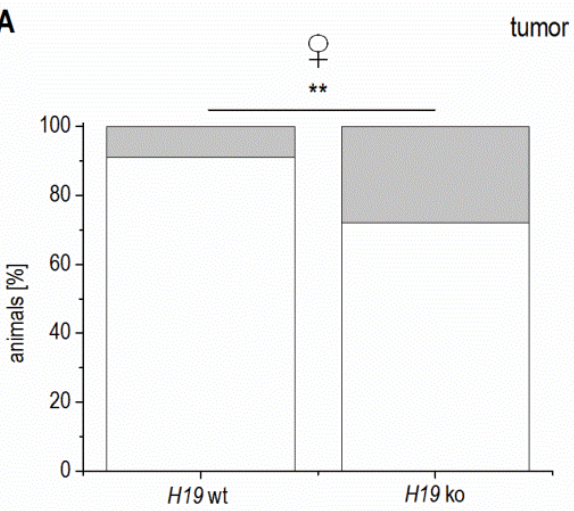

umor development in DEN treated mice
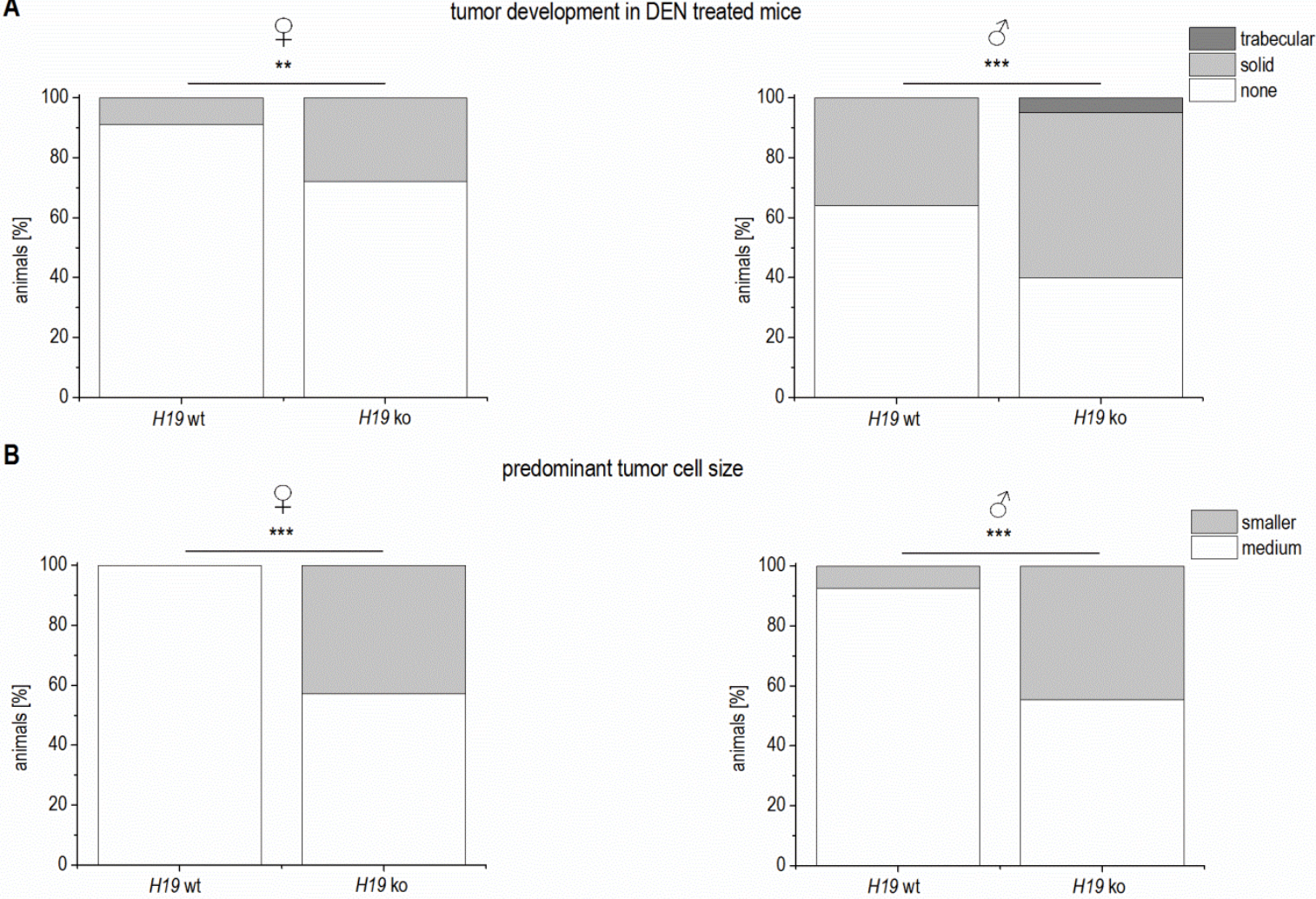

B

predominant tumor cell size

C

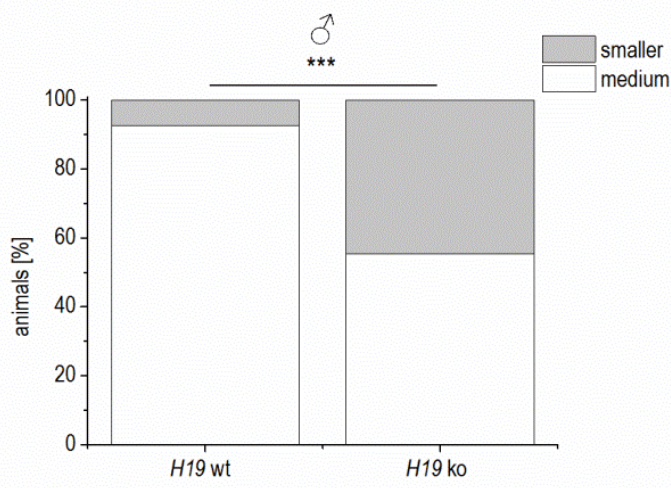

staining of proliferation marker Ki67

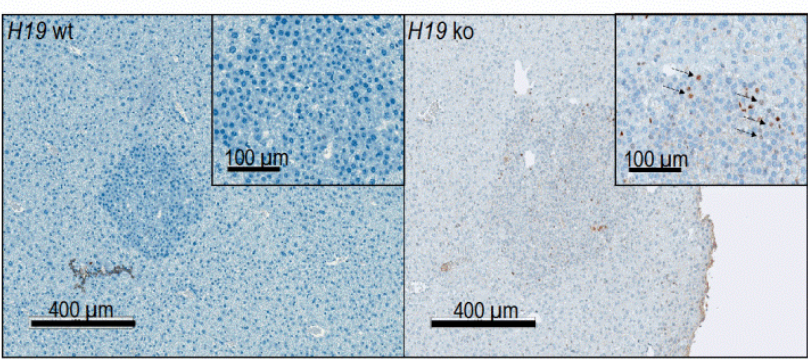

D

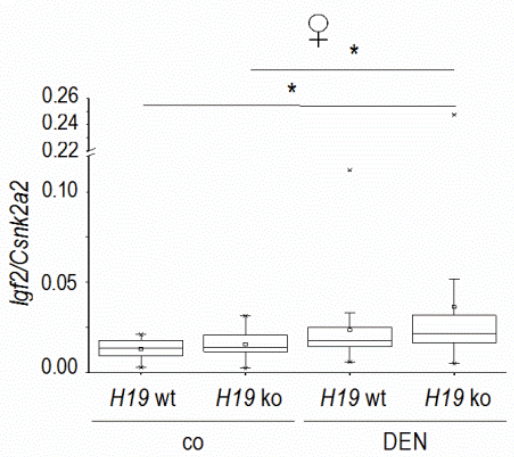

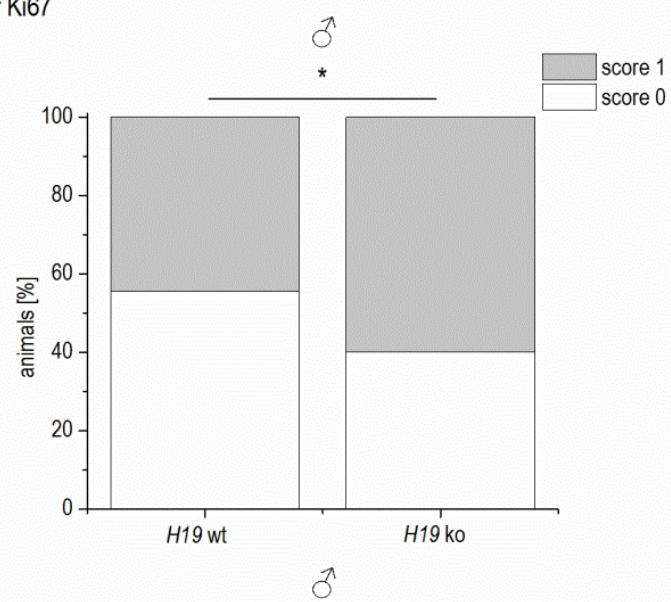

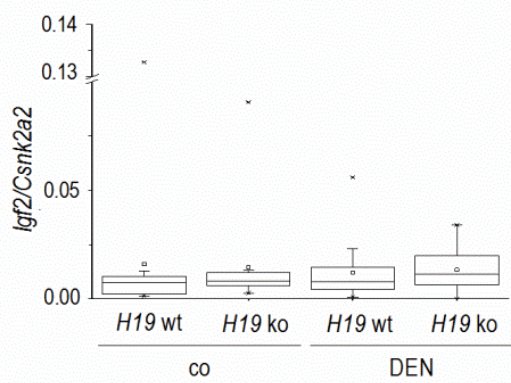

FIGURE 9: Tumor development and characterization in long-term DEN treated $H 19$ knockout ( $H 19$ ko) compared to $H 19$ wild-type (H19 wt) mice. (A) Tumor development in female (left) and male (right) DEN treated mice (female: H19 wt n=22, H19 ko n=25; male: H19 wt n=25, H19 ko n=20). (B) Predominant cell size in tumors of DEN treated female (left) and male (right) mice. (C) Representative immunohistological staining of proliferation marker Ki67 (left, score 0: no proliferating cells detectable; score 1: less than 1\% proliferating cells with brown stained nuclei (arrow)) and expression of Ki67 in tumors of male DEN treated mice (right, H19 wt $n=9, H 19$ ko $n=10$ ). (A-C) The $p$ values were calculated by Chi-square test. * $p<0.05, * * p<0.01, * * * p$ $<0.001$. (D) Igf2 expression in female (left) and male (right) control (co) and DEN treated (DEN) mice determined by qPCR (female: H19 wt co $\mathrm{n}=11$, $H 19$ ko co $n=23, H 19$ wt DEN $n=22, H 19$ ko DEN $n=25$; male $H 19$ wt co $n=13, H 19$ ko co $n=18, H 19$ wt DEN $n=25, H 19$ ko DEN $n=20$ ). The $p$ values were calculated by Mann-Whitney $U$ test. $* \mathrm{p}<0.0125$. 
after digestion. In case of monoallelic expression, cDNA was expected to show one $148 \mathrm{bp}$ band and three bands (48 bp, $100 \mathrm{bp}$, and $148 \mathrm{bp}$ ) in case of biallelic expression. Due to the high agarose concentration (3\%), the $48 \mathrm{bp}$ band was not detectable.

\section{Cell culture}

HepG2, Huh7, and PIc/Prf/5 cells were cultured in RPMI-1640 medium with $10 \%$ fetal calf serum, $1 \%$ penicillin/streptomycin, and $1 \%$ glutamine (Sigma-Aldrich, Taufkirchen, Germany) at $37^{\circ} \mathrm{C}$ and $5 \% \mathrm{CO} 2$.

\section{Establishment of chemoresistant cells}

Doxorubicin-resistant (HepG2-Dox-R, Huh7-Dox-R, and $\mathrm{Plc} /$ Prf/5-Dox-R) and sorafenib-resistant (HepG2-Sora-R, Huh7-Sora-R, and Plc/Prf/5-Sora-R) cells were established by treatment with increasing concentrations of the cytostatic drugs over several months. In order to maintain the resistance, cells were treated biweekly with doxorubicin (HepG2-Dox-R: 1 $\mu \mathrm{g} / \mathrm{ml}$, Huh7-Dox-R: $0.2 \mu \mathrm{g} / \mathrm{ml}$, and Plc/Prf/5-Dox-R: $2 \mu \mathrm{g} / \mathrm{ml}$ ) or sorafenib (HepG2-Sora-R, Huh7-Sora-R, and Plc/Prf/5-SoraR: $10 \mu \mathrm{M}$ ) for $24 \mathrm{~h}$. Chemoresistance was confirmed by MTT assay.

\section{Stable and transient $\mathrm{H} 19$ overexpression}

Stable $H 19$ overexpression in hepatoma cells was established by transfection with a vector (pcDNa3.1(+)_A009) containing the synthetic H19-sequence or the empty vector as control (Figure S1) (Ref. No.: 1381790, Life Technologies, California, USA) using jetPEI ${ }^{\mathrm{TM}}$ Hepatocyte reagent (102-05N, VWR International $\mathrm{GmbH}$, Darmstadt, Germany) as recommended by the manufacturer. The final vector construct was verified by sequencing. Resistance to geneticin (G418, Invitrogen, Darmstadt, Germany) was conferred by the neomycin resistance gene $(\mathrm{Neo}(\mathrm{R}))$.

Transient $H 19$ overexpression in chemoresistant cells was performed accordingly, but cells were treated with doxorubicin or sorafenib (HepG2-Dox-R: $2 \mu \mathrm{g} / \mathrm{ml}$; Huh7-Sora-R: $2.5 \mu \mathrm{M}$ ) simultaneously with the plasmid transfection. H19 overexpression was confirmed by qPCR.

\section{H19 knockdown}

H19 knockdown was performed in 96-well plates with antisense LNATM gapmer (Exiqon, Vedbaek, Denmark) for H19 (5'GACTTAGTGCAAATTA- $\left.3^{\prime}\right)$ or negative control A (5'AACACGTCTATACGC-3') (gapmer concentration per well: HepG2: $0.04 \mu \mathrm{M}, \mathrm{Plc} / \mathrm{Prf} / 5$ : $0.02 \mu \mathrm{M}$, and Huh7: $0.03 \mu \mathrm{M}$ ) using INTERFERin ${ }^{\circledR}$ (Polyplus-Transfection, Illkirch, France) transfection reagent as recommended by the manufacturer. The negative control shows no homology to any known microRNA, IncRNA, or mRNA. H19 knockdown was confirmed by qPCR.

\section{Cytotoxicity assay (MTT assay)}

Hepatoma cells were seeded into 96-well plates and treated with different concentrations of doxorubicin (Sigma-Aldrich, Taufkirchen, Germany), sorafenib (Biomol GmbH, Hamburg, Germany), or the respective solvent control. $24 \mathrm{~h}$ after treatment, medium was removed and $0.5 \mathrm{mg} / \mathrm{ml}$ MTT (3-[4,5dimethylthiazol-2-yl]-2,5- diphenyltetrazolium bromide; thiazolyl blue) (Sigma-Aldrich, Taufkirchen, Germany) diluted in medium was added. After $2 \mathrm{~h}$ incubation, the formazan crystals were dissolved in dimethyl sulfoxide, and the absorbance was measured at $550 \mathrm{~nm}$ with $630 \mathrm{~nm}$ as reference wavelength in a microplate reader (Tecan Sunrise ${ }^{\mathrm{TM}}$, Tecan Group Ltd., Männedorf, Switzerland) [64, 65].

For the MTT assay after 5-azacytidine treatment, cells were treated over four days with $2 \mu \mathrm{M}$ of the DNAmethyltransferases inhibitor 5-azacytidine (Sigma-Aldrich, Taufkirchen, Germany), which was freshly added each day.

\section{Clonogenicity assay}

The hepatoma cells HepG2, Huh7, and PIc/Prf/5 were seeded into 6-well plates, allowed to attach overnight, and treated with the indicated concentrations of sorafenib or doxorubicin for another $24 \mathrm{~h}$. Following the treatment, cells were washed with PBS and allowed to form colonies in complete growth medium. After 10 to 15 days, the colonies were fixed in methanol, stained with crystal violet, and counted. For the sorafenib experiments colonies were counted with a clono counter software as previously described $[66,67]$ and for the doxorubicin experiments colonies were counted manually.

\section{Ki67 staining}

Cells were detached from the plates using trypsin (SigmaAldrich, Taufkirchen, Germany) and cell staining was performed as described previously [51]. For intracellular staining of Ki67, cells were washed with flow cytometry buffer (FCB; PBS containing $2.5 \%(\mathrm{v} / \mathrm{v})$ bovine calf serum and $0.05 \%(\mathrm{w} / \mathrm{v})$ NaN3) and fixed for $10 \mathrm{~min}$ in $1 \%(\mathrm{w} / \mathrm{v})$ paraformaldehyde in PBS, pH 7.6, followed by permeabilization in SAP (FCB with $0.2 \%(\mathrm{w} / \mathrm{v})$ saponin, and blocking for $30 \mathrm{~min}$ in $20 \% \mathrm{FCS}(\mathrm{v} / \mathrm{v}$, diluted in SAP). Cells were incubated with Ki67 or isotype control antibody ( $10 \mu \mathrm{l}$ in $50 \mu \mathrm{l}$ of FCB; BD Biosciences Heidelberg, Germany) for $15 \mathrm{~min}$ on ice. The cells were washed in $\mathrm{FCB}$ and resuspended in $1 \%(\mathrm{w} / \mathrm{v})$ cold paraformaldehyde in $\mathrm{PBS}, \mathrm{pH}$ 7.6. The stained cells were examined on a BD LSRFortessa ${ }^{\mathrm{TM}}$ cell analyser and results were analyzed using the FACS Diva software (BD Biosciences, Heidelberg, Germany).

\section{DNA methylation analysis \\ DNA extraction and bisulfite conversion}

Genomic DNA from HepG2, Plc/Prf/5, and Huh7 cells was extracted with the GenEluteTM Mammalian Genomic DNA Miniprep Kit (Sigma-Aldrich, Taufkirchen, Germany) and bisulfite treatment of $500 \mathrm{ng}$ genomic DNA was performed with the EZ DNA Methylation-Gold Kit (Zymo Research, Freiburg, Germany) according to the manufacturer's instructions.

\section{Single nucleotide primer extension (SNuPE)}

Amplicons were generated using a previously described protocol [68] and region-specific primers for the $H 19$ promoter (10 $\mu \mathrm{M}$ each): forward (5'-3'): GGGTTTGGGAGAGTTTGTGAGGT; reverse $\left(5^{\prime}-3^{\prime}\right)$ : AACACAAAAAACCCCTTCCTACCA. The PCR reaction conditions were $15 \mathrm{~min}$ at $95^{\circ} \mathrm{C}$ followed by 42 cycles of $95^{\circ} \mathrm{C}$ for $60 \mathrm{~s}, 57.6^{\circ} \mathrm{C}$ for $60 \mathrm{~s}, 72^{\circ} \mathrm{C}$ for $60 \mathrm{~s}$, and a final $5 \mathrm{~min}$ extension at $72^{\circ} \mathrm{C}$. The single nucleotide primer extension for two CpG sites of the $\mathrm{H} 19$ promoter (CpG 3 primer $\left(5^{\prime}-3^{\prime}\right)$ TGTTAGTAGAGTG and CpG 17 primer $\left(5^{\prime}-3^{\prime}\right)$ : GTGATTAGTATAAGTT) was performed as previously described [42].

\section{Local deep bisulfite sequencing (Bi-PROF)}

For the analysis with next generation sequencing, the recommended adaptors were added to the primer sequences for the amplicon generation (forward (5'-3'): TCTTTCCCTACACGAC- 
GCTCTTCCGATCTGGGTTTGGGAGAGTTTGTGAGGT and reverse $\left(5^{\prime}-3^{\prime}\right)$ : GTGACTGGAGTTCAGACGTGTGCTCTTCCGATCTAACACAAAAAACC CCTTCCTACCA, annealing temperature $60^{\circ} \mathrm{C}$ ). Purified PCR products were pooled in an equimolar ratio and sequenced [69] on a MiSeq instrument with the sequencing-by-synthesis technology $(2 \times 300$ bp paired-end) aiming at 10,000 reads per amplicon according to the manufacturer's protocol.

\section{DEN mouse model}

All animal procedures were performed in accordance with the local animal welfare committee $(36 / 2013,36 / 2014)$. Mice were kept under controlled conditions regarding temperature, humidity, $12 \mathrm{~h}$ day/night rhythm, and food access.

For the long-term experiment, $H 19$ knockout $(H 19 \Delta 3 ; H 19$ ko) mice $[48,70]$ matched with wild-type (wt) littermates were intraperitoneally injected with $5 \mathrm{mg} / \mathrm{kg}$ body weight diethylnitrosamine (DEN) (Sigma-Aldrich, Taufkirchen, Germany) at the age of two weeks and sacrificed 24 weeks after injection. Untreated mice served as control (co) (female: $\mathrm{H} 19 \mathrm{wt}$ co $n=11, H 19$ ko co $n=23, H 19$ wt DEN $n=22, H 19$ ko DEN $n=25$; male $H 19$ wt co $n=13, H 19$ ko co $n=18, H 19$ wt DEN $n=25, H 19$ ko $D E N n=20)[71,72]$.

For the short-term experiment nine week old male mice were intraperitoneally injected with either $100 \mathrm{mg} / \mathrm{kg}$ body weight $\mathrm{DEN}$ or $\mathrm{NaCl}$ as a sham-control (each, $\mathrm{n}=5$ ). Mice were sacrificed $48 \mathrm{~h}$ after the injection [72-74].

\section{Immunohistochemistry}

Hematoxylin-eosin staining and immunohistological staining for the proliferation marker Ki67 on paraffin-embedded tissues and sample examination were performed as previously described $[19,72,75]$.

\section{Chromogenic in situ hybridization (CISH)}

Eight paraffin-embedded samples from HCC patients were investigated. The reseach project was authorized by the ethical committee of the Medical University of Graz (Ref. Nr. 20119 ex 08/09). CISH was performed using the miCURY LNATM microRNA ISH Optimization Kit (FFPE) (Exiqon, Vedbaek, Denmark) according to manufacturer's instruction. A biotinlabeled probe was used for the detection of H19 RNA (/5BioTEG/GTCCTGTAACCAAAAGTGACCG, Exiqon, Vedbaek, Denmark). A digoxin-labeled probe of scrambled RNA served as negative control (/5DigN/GTGTAACACGTCTATACGCCCA, Exiqon, Vedbaek, Denmark) and a digoxin-labeled beta-actin probe was used as positive control (/5DigN/CTCATTGTAGAAGGTGTGGTGCCA, Exiqon, Vedbaek, Denmark). All probes were used in a concentration of $40 \mathrm{nM}$. Proteinase $\mathrm{K}$ digestion was done for $10 \mathrm{~min}$ at $37^{\circ} \mathrm{C}$ with 15 $\mu \mathrm{g} / \mathrm{ml}$ Proteinase K (Roche, Mannheim, Germany). The hybridization step was performed at $56^{\circ} \mathrm{C}$ for $1 \mathrm{~h}$ in a slide hybridizer DakoCytomation (Dako, Hamburg, Germany). Nuclei were counterstained with Nuclear Fast Red Counterstain (Vector Laboratories, Burlingname, CA, USA).

\section{REFERENCES}

1.Consortium IHGS (2004). Finishing the euchromatic sequence of the human genome. Nature 431: 931-945. doi:10.1038/nature03001

\section{Statistical analysis}

Data analysis and statistics were performed with Excel 2013 and OriginPro 8.6G (OriginLab Corporation, Northampton, USA). Values were expressed as mean \pm SEM or as box plots with 25th/75th percentile boxes, geometric medians (line), means (square), and 10th/90th percentile as whiskers. Statistical differences were calculated using an independent twosample t-test, Mann-Whitney U test, or Kolmogorov-Smirnov test as indicated depending on whether the data were normally distributed. A chi-square test was used for the statistical analysis of tumor development and characterization in mouse livers.

\section{ACKNOWLEDGEMENTS}

We thank Theo Ranßweiler, Margit Gogg-Kammerer, Jasmin Kirch, Beate Schmitt, Mohamed Al-Effah, and Julia Michaely for excellent technical assistance. We thank Eva Dilly for help in animal care. The project was funded, in part, by the Else Kröner-Fresenius-Stiftung (2012_A250 to AKK and SMK), an EASL Dame Sheila Sherlock Fellowship (to SMK), a Bank Austria Visiting Scientists Programme Fellowship (to SMK), the Deutsche Krebshilfe (107751 to $A K K)$, the Boehringer Ingelheim Fonds (to $C S$ ), the Dr. Hilmer Stiftung (to KH), and the BMBF LiSyM 031L0051 (to $\mathrm{FL}$ ). The results upon which this publication is based were partly funded by the Federal Ministry of Education and Research under the Project Number [01KU1216F] (to AKK). The responsibility for the content of this publication lies with the authors.

\section{SUPPLEMENTAL MATERIAL}

All supplemental data for this article are available online at www.cell-stress.com.

\section{CONFLICT OF INTEREST}

The authors declare that there is no conflict of interest to disclose.

\section{COPYRIGHT}

(C) 2017 Schultheiss et al. This is an open-access article released under the terms of the Creative Commons Attribution (CC BY) license, which allows the unrestricted use, distribution, and reproduction in any medium, provided the original author and source are acknowledged.

Please cite this article as: Christina S. Schultheiss, Stephan Laggai, Beate Czepukojc, Usama K. Hussein, Markus List, Ahmad Barghash, Sascha Tierling, Kevan Hosseini, Nicole Golob-Schwarzl, Juliane Pokorny, Nina Hachenthal, Marcel Schulz, Volkhard Helms, Jörn Walter, Vincent Zimmer, Frank Lammert, Rainer M. Bohle, Luisa Dandolo, Johannes Haybaeck, Alexandra K. Kiemer, Sonja M. Kessler (2017). The long non-coding RNA H19 suppresses carcinogenesis and chemoresistance in hepatocellular carcinoma. Cell Stress 1(1): 37-54. doi: 10.15698/cst2017.10.105

2. Wang WT, Ye H, Wei PP, Han BW, He B, Chen ZH, Chen YQ (2016). LncRNAs $\mathrm{H} 19$ and HULC, activated by oxidative stress, promote cell 
migration and invasion in cholangiocarcinoma through a ceRNA manner. J Hematol Oncol 9: 117. doi:10.1186/s13045-016-0348-0

3. Ohtsuka $M$, Ling $H$, Ivan $C$, Pichler $M$, Matsushita D, Goblirsch $M$, Stiegelbauer V, Shigeyasu K, Zhang X, Chen M, Vidhu F, Bartholomeusz GA, Toiyama Y, Kusunoki M, Doki Y, Mori M, Song S, Gunther JR, Krishnan S, Slaby O, Goel A, Ajani JA, Radovich M, Calin GA (2016). H19 Noncoding RNA, an Independent Prognostic Factor, Regulates Essential Rb-E2F and CDK8-beta-Catenin Signaling in Colorectal Cancer. EBioMedicine 13: 113-124. doi:10.1016/j.ebiom.2016.10.026

4. Li X, Wang H, Yao B, Xu W, Chen J, Zhou X (2016). IncRNA H19/miR675 axis regulates cardiomyocyte apoptosis by targeting VDAC1 in diabetic cardiomyopathy. Sci Rep 6: 36340. doi:10.1038/srep36340

5. Chen SW, Wang PY, Liu YC, Sun L, Zhu J, Zuo S, Ma J, Li TY, Zhang JL, Chen GW, Wang X, Zhu QR, Zheng YW, Chen ZY, Yao ZH, Pan YS (2016). Effect of Long Noncoding RNA H19 Overexpression on Intestinal Barrier Function and Its Potential Role in the Pathogenesis of Ulcerative Colitis. Inflamm Bowel Dis 22: 2582-2592. doi:10.1097/MIB.0000000000000932

6. Cai X, Cullen BR (2007). The imprinted $H 19$ noncoding RNA is a primary microRNA precursor. RNA 13: 313. doi: 10.1261/rna.351707

7. Keniry A, Oxley D, Monnier P, Kyba M, Dandolo L, Smits G, Reik W (2012). The $H 19$ lincRNA is a developmental reservoir of miR-675 that suppresses growth and Igf1r. Nat Cell Biol 14: 659-665. doi: $10.1038 / \mathrm{ncb} 2521$

8. Raveh E, Matouk IJ, Gilon M, Hochberg A (2015). The H19 Long noncoding RNA in cancer initiation, progression and metastasis - a proposed unifying theory. Mol Cancer 14: 184. doi:10.1186/s12943015-0458-2

9. Kohno $T$, Tsuge $M$, Murakami E, Hiraga $N$, Abe $H$, Miki D, Imamura $\mathrm{M}$, Ochi $\mathrm{H}$, Hayes $\mathrm{CN}$, Chayama $\mathrm{K}$ (2014). Human microRNA hsa-miR1231 suppresses hepatitis $B$ virus replication by targeting core mRNA. J Viral Hepat 21: e89-97. doi:10.1111/jvh.12240

10. Lu TX, Sherrill JD, Wen T, Plassard AJ, Besse JA, Abonia JP, Franciosi JP, Putnam PE, Eby M, Martin $L$, Aronow BJ, Rothenberg ME (2012). MicroRNA signature in patients with eosinophilic esophagitis, reversibility with glucocorticoids, and assessment as disease biomarkers. J Allergy Clin Immunol 129: 1064-1075. doi:10.1016/j.jaci.2012.01.060

11. El-Serag HB, Rudolph KL (2007). Hepatocellular carcinoma: epidemiology and molecular carcinogenesis. Gastroenterology 132: 2557-2576. doi:10.1053/j.gastro.2007.04.061

12. Stewart BW, Wild CP (2014). World cancer report 2014. International Agency for Research on Cancer. Available at: www.iarc.fr/en/publications/books/wcr/wcr-order.php [Accessed 06.02.2014]

13. Yoshimizu T, Miroglio A, Ripoche MA, Gabory A, Vernucci M, Riccio A, Colnot S, Godard C, Terris B, Jammes H, Dandolo L (2008). The H19 locus acts in vivo as a tumor suppressor. Proc Natl Acad Sci U S A 105 : 12417-12422. doi: 10.1073/pnas.0801540105

14. Matouk IJ, DeGroot N, Mezan S, Ayesh S, Abu-lail R, Hochberg A, Galun E (2007). The $H 19$ non-coding RNA is essential for human tumor growth. PLoS One 2: e845. doi:10.1371/journal.pone.0000845

15. Gabory A, Ripoche MA, Yoshimizu T, Dandolo L (2006). The H19 gene: regulation and function of a non-coding RNA. Cytogenet Genome Res 113: 188-193. doi:10.1159/000090831
16. Kim KS, Lee YI (1997). Biallelic expression of the $H 19$ and IGF2 genes in hepatocellular carcinoma. Cancer Lett 119: 143-148. doi: 10.1016/s0304-3835(97)00264-4

17. Wu J, Qin Y, Li B, He WZ, Sun ZL (2008). Hypomethylated and hypermethylated profiles of H19DMR are associated with the aberrant imprinting of IGF2 and $\mathrm{H} 19$ in human hepatocellular carcinoma. Genomics 91: 443-450. doi:10.1016/j.ygeno.2008.01.007

18. Kessler SM, Pokorny J, Zimmer V, Laggai S, Lammert F, Bohle RM, Kiemer AK (2013). IGF2 mRNA binding protein p62/IMP2-2 in hepatocellular carcinoma: antiapoptotic action is independent of IGF2/PI3K signaling. Am J of Physiol Gastrointest Liver Physiol 304: G328-G336 doi:10.1152/ajpgi.00005.2012

19. Kessler SM, Simon Y, Gemperlein K, Gianmoena K, Cadenas C, Zimmer V, Pokorny J, Barghash A, Helms V, van Rooijen N, Bohle RM, Lammert F, Hengstler JG, Mueller R, Haybaeck J, Kiemer AK (2014). Fatty acid elongation in non-alcoholic steatohepatitis and hepatocellular carcinoma. Int J Mol Sci 15: 5762-5773. doi:10.3390/ijms15045762

20. Gao ZH, Suppola S, Liu J, Heikkila P, Janne J, Voutilainen R (2002). Association of $\mathrm{H} 19$ promoter methylation with the expression of $\mathrm{H} 19$ and IGF-II genes in adrenocortical tumors. J Clin Endocrinol Metab 87: 1170-1176. doi:10.1210/jcem.87.3.8331

21. Hadji F, Boulanger MC, Guay SP, Gaudreault N, Amellah S, Mkannez G, Bouchareb R, Marchand JT, Nsaibia MJ, Guauque-Olarte S, Pibarot P, Bouchard L, Bosse Y, Mathieu P (2016). Altered DNA Methylation of Long Noncoding RNA $\mathrm{H} 19$ in Calcific Aortic Valve Disease Promotes Mineralization by Silencing NOTCH1. Circulation 134: 1848-1862. doi:10.1161/CIRCULATIONAHA.116.023116

22. Franken NA, Rodermond HM, Stap J, Haveman J, van Bree C (2006). Clonogenic assay of cells in vitro. Nat Protoc 1: 2315-2319. doi:10.1038/nprot.2006.339

23. Germano D, Daniele B (2014). Systemic therapy of hepatocellular carcinoma: current status and future perspectives. World J Gastroenterol 20: 3087-3099. doi:10.3748/wjg.v20.i12.3087

24. Lencioni R, Llovet JM, Han G, Tak WY, Yang J, Guglielmi A, Paik SW, Reig M, Kim do Y, Chau GY, Luca A, del Arbol LR, Leberre MA, Niu W, Nicholson K, Meinhardt G, Bruix J (2016). Sorafenib or placebo plus TACE with doxorubicin-eluting beads for intermediate stage HCC: The SPACE trial. J Hepatol 64: 1090-1098. doi:10.1016/j.jhep.2016.01.012

25. Rachmilewitz J, Goshen R, Ariel I, Schneider T, de Groot N, Hochberg A (1992). Parental imprinting of the human $\mathrm{H} 19$ gene. FEBS Lett 309: 25-28. doi: 10.1016/0014-5793(92)80731-u

26. Nakatani T, Roy G, Fujimoto N, Asahara T, Ito A (2001). Sex hormone dependency of diethylnitrosamine-induced liver tumors in mice and chemoprevention by leuprorelin. Jpn J Cancer Res 92: 249256. doi:10.1111/j.1349-7006.2001.tb01089.x

27. Pachnis V, Belayew A, Tilghman SM (1984). Locus unlinked to alpha-fetoprotein under the control of the murine raf and Rif genes. Proc Natl Acad Sci U S A 81: 5523-5527. doi:10.1073/pnas.81.17.5523

28. Bartolomei MS, Zemel S, Tilghman SM (1991). Parental imprinting of the mouse $H 19$ gene. Nature 351: 153-155. doi:10.1038/351153a0

29. Tilghman SM, Bartolomei MS, Webber AL, Brunkow ME, Saam J, Leighton PA, Pfeifer K, Zemel S (1993). Parental imprinting of the H19 and Igf2 genes in the mouse. Cold Spring Harb Symp Quant Biol 58: 287-295. doi:10.1101/SQB.1993.058.01.034 
30. Zhang L, Yang F, Yuan JH, Yuan SX, Zhou WP, Huo XS, Xu D, Bi HS, Wang F, Sun SH (2013). Epigenetic activation of the MiR-200 family contributes to $\mathrm{H} 19$-mediated metastasis suppression in hepatocellular carcinoma. Carcinogenesis 34: 577-586. doi:10.1093/carcin/bgs381

31. Ariel I, Miao HQ, Ji XR, Schneider T, Roll D, de Groot N, Hochberg A, Ayesh S (1998). Imprinted $\mathrm{H} 19$ oncofetal RNA is a candidate tumour marker for hepatocellular carcinoma. Mol Pathol 51: 21-25. doi:10.1136/mp.51.1.21

32. Fellig $\mathrm{Y}$, Ariel I, Ohana $\mathrm{P}$, Schachter $\mathrm{P}$, Sinelnikov $\mathrm{I}$, Birman $\mathrm{T}$, Ayesh S, Schneider T, de Groot N, Czerniak A, Hochberg A (2005). H19 expression in hepatic metastases from a range of human carcinomas. J Clin Pathol 58: 1064-1068. doi:10.1136/jcp.2004.023648

33. Sohda T, Iwata K, Soejima H, Kamimura S, Shijo H, Yun K (1998). In situ detection of insulin-like growth factor II (IGF2) and $\mathrm{H} 19$ gene expression in hepatocellular carcinoma. J Hum Genet 43: 49-53. doi:10.1007/s100380050036

34. Okada H, Kimura MT, Tan D, Fujiwara K, Igarashi J, Makuuchi M, Hui AM, Tsurumaru M, Nagase H (2005). Frequent trefoil factor 3 (TFF3) overexpression and promoter hypomethylation in mouse and human hepatocellular carcinomas. Int J Oncol 26: 369-377. doi:10.3892/ijo.26.2.369

35. Kong LM, Liao CG, Chen L, Yang HS, Zhang SH, Zhang Z, Bian HJ, Xing JL, Chen ZN (2011). Promoter hypomethylation up-regulates CD147 expression through increasing Sp1 binding and associates with poor prognosis in human hepatocellular carcinoma. J Cell Mol Med 15: 1415-1428. doi:10.1111/j.1582-4934.2010.01124.x

36. Yang B, Liu Y, Zhao J, Hei K, Zhuang H, Li Q, Wei W, Chen R, Zhang $\mathrm{N}$, Li Y (2017). Ectopic overexpression of filamin C scaffolds MEK1/2 and ERK1/2 to promote the progression of human hepatocellular carcinoma. Cancer Lett 388: 167-176. doi:10.1016/j.canlet.2016.11.037

37. Ding Z, Qian YB, Zhu LX, Xiong QR (2009). Promoter methylation and mRNA expression of DKK-3 and WIF-1 in hepatocellular carcinoma. World J Gastroenterol 15: 2595-2601. doi:10.3748/wjg.15.2595

38. Wagner JR, Busche S, Ge B, Kwan T, Pastinen T, Blanchette M (2014). The relationship between DNA methylation, genetic and expression inter-individual variation in untransformed human fibroblasts. Genome Biol 15: R37. doi:10.1186/gb-2014-15-2-r37

39. Kim YI, Giuliano A, Hatch KD, Schneider A, Nour MA, Dallal GE, Selhub J, Mason JB (1994). Global DNA hypomethylation increases progressively in cervical dysplasia and carcinoma. Cancer 74: 893-899. doi: $\quad$ 10.1002/1097-0142(19940801)74:3<893::aidcncr2820740316>3.0.co;2-b

40. Lin CH, Hsieh SY, Sheen IS, Lee WC, Chen TC, Shyu WC, Liaw YF (2001). Genome-wide hypomethylation in hepatocellular carcinogenesis. Cancer Res 61: 4238. PMID: 11358850

41. Shen L, Fang J, Qiu D, Zhang T, Yang J, Chen S, Xiao S (1998). Correlation between DNA methylation and pathological changes in human hepatocellular carcinoma. Hepatogastroenterology 45: 1753 1759. PMID: 9840141

42. Diesel B, Ripoche N, Risch RT, Tierling S, Walter J, Kiemer AK (2012). Inflammation-induced up-regulation of TLR2 expression in human endothelial cells is independent of differential methylation in the TLR2 promoter CPG island. Innate Immun 18: 112-123. doi:10.1177/1753425910394888
43. Zhou J, Yang L, Zhong T, Mueller M, Men Y, Zhang N, Xie J, Giang K, Chung H, Sun X, Lu L, Carmichael GG, Taylor HS, Huang Y (2015). H19 IncRNA alters DNA methylation genome wide by regulating Sadenosylhomocysteine hydrolase. Nat Commun 6: 10221. doi:10.1038/ncomms10221

44. Festuccia C, Gravina GL, D'Alessandro AM, Muzi P, Millimaggi D, Dolo V, Ricevuto E, Vicentini C, Bologna M (2009). Azacitidine improves antitumor effects of docetaxel and cisplatin in aggressive prostate cancer models. Endocr Relat Cancer 16: 401-413. doi:10.1677/ERC-08-0130

45. Tsang WP, Kwok TT (2007). Riboregulator H19 induction of MDR1associated drug resistance in human hepatocellular carcinoma cells. Oncogene 26: 4877-4881. doi:10.1038/sj.onc.1210266

46. Moore T, Haig D (1991). Genomic imprinting in mammalian development: a parental tug-of-war. Trends Genet 7: 45-49. doi:10.1016/0168-9525(91)90230-N

47. Leighton PA, Ingram RS, Eggenschwiler J, Efstratiadis A, Tilghman SM (1995). Disruption of imprinting caused by deletion of the H19 gene region in mice. Nature 375: 34-39. doi:10.1038/375034a0

48. Ripoche MA, Kress C, Poirier F, Dandolo $L$ (1997). Deletion of the $\mathrm{H} 19$ transcription unit reveals the existence of a putative imprinting control element. Genes Dev 11: 1596-1604. doi:10.1101/gad.11.12.1596

49. Yu YQ, Weng J, Li SQ, Li B, Lv J (2016). MiR-675 Promotes the Growth of Hepatocellular Carcinoma Cells Through the Cdc25A Pathway. Asian Pac J Cancer Prev 17: 3881-3885. PMID:27644634

50. Martinet C, Monnier P, Louault Y, Benard M, Gabory A, Dandolo L (2016). H19 controls reactivation of the imprinted gene network during muscle regeneration. Development 143: 962-971. doi:10.1242/dev.131771

51. Hoppstadter J, Hachenthal N, Valbuena-Perez JV, Lampe $\mathrm{S}$ Astanina K, Kunze MM, Bruscoli S, Riccardi C, Schmid T, Diesel B, Kiemer AK (2016). Induction of Glucocorticoid-induced Leucine Zipper (GILZ) Contributes to Anti-inflammatory Effects of the Natural Product Curcumin in Macrophages. J Biol Chem 291: 22949-22960. doi:10.1074/jbc.M116.733253

52. Vazquez-Chantada $M$, Fernandez-Ramos D, Embade $N$, MartinezLopez N, Varela-Rey M, Woodhoo A, Luka Z, Wagner C, Anglim PP, Finnell RH, Caballeria J, Laird-Offringa IA, Gorospe M, Lu SC, Mato JM, Martinez-Chantar ML (2010). HuR/methyl-HuR and AUF1 regulate the MAT expressed during liver proliferation, differentiation, and carcinogenesis. Gastroenterology 138: 1943-1953. doi:10.1053/j.gastro.2010.01.032

53. Zhu H, Berkova Z, Mathur R, Sehgal L, Khashab T, Tao RH, Ao X, Feng L, Sabichi AL, Blechacz B, Rashid A, Samaniego F (2015). HuR Suppresses Fas Expression and Correlates with Patient Outcome in Liver Cancer. Mol Cancer Res 13: 809-818. doi:10.1158/1541 7786.MCR-14-0241

54. Zhang LF, Lou JT, Lu MH, Gao C, Zhao S, Li B, Liang S, Li Y, Li D, Liu MF (2015). Suppression of miR-199a maturation by HuR is crucial for hypoxia-induced glycolytic switch in hepatocellular carcinoma. EMBO J 34: 2671-2685. doi:10.15252/embj.201591803

55. Colaprico A, Silva TC, Olsen C, Garofano L, Cava C, Garolini D, Sabedot TS, Malta TM, Pagnotta SM, Castiglioni I, Ceccarelli M, Bontempi G, Noushmehr H (2016). TCGAbiolinks: an R/Bioconductor package for integrative analysis of TCGA data. Nucleic Acids Res 44: e71. doi:10.1093/nar/gkv1507 
56. Li B, Dewey CN (2011). RSEM: accurate transcript quantification from RNA-Seq data with or without a reference genome. BMC Bioinformatics 12: 323. doi:10.1186/1471-2105-12-323

57. Fink L, Kinfe T, Stein MM, Ermert L, Hanze J, Kummer W, Seeger W, Bohle RM (2000). Immunostaining and laser-assisted cell picking for mRNA analysis. Lab Invest 80: 327-333. doi: 10.1038/labinvest.3780037

58. Fink L, Stahl U, Ermert L, Kummer W, Seeger W, Bohle RM (1999). Rat porphobilinogen deaminase gene: a pseudogene-free internal standard for laser-assisted cell picking. Biotechniques 26: 510-516. PMID: 10090993

59. Dembek A, Laggai S, Kessler SM, Czepukojc B, Simon Y, Kiemer AK, Hoppstädter J (2017). Hepatic interleukin-6 production is maintained during endotoxin tolerance and facilitates lipid accumulation. Immunobiology 222(6): 786-796. doi:10.1016/j.imbio.2017.01.003

60. Kessler SM, Laggai S, Van Wonterg E, Gemperlein K, Müller R, Haybaeck J, Vandenbroucke RE, Ogris M, Libert C, Kiemer AK (2016). Transient hepatic overexpression of insulin-like growth factor 2 induces free cholesterol and lipid droplet formation. Front Physiol 7 : 147. doi:10.3389/fphys.2016.00147

61. Kiemer AK, Senaratne RH, Hoppstadter J, Diesel B, Riley LW, Tabeta K, Bauer S, Beutler B, Zuraw BL (2009). Attenuated activation of macrophage TLR9 by DNA from virulent mycobacteria. J Innate Immun 1: 29-45. doi:10.1159/000142731

62. Laggai S, Kessler SM, Boettcher S, Lebrun V, Gemperlein K, Lederer E, Leclercq IA, Mueller R, Hartmann RW, Haybaeck J, Kiemer AK (2014). The IGF2 mRNA binding protein p62/IGF2BP2-2 induces fatty acid elongation as a critical feature of steatosis. J Lipid Res 55: 10871097. doi:10.1194/jlr.M045500

63. Zhang Y, Tycko B (1992). Monoallelic expression of the human $\mathrm{H} 19$ gene. Nat Genet 1: 40-44. doi: 10.1038/ng0492-40

64. Astanina K, Simon Y, Cavelius C, Petry S, Kraegeloh A, Kiemer AK (2014). Superparamagnetic iron oxide nanoparticles impair endothelial integrity and inhibit nitric oxide production. Acta Biomater 10: 4896-4911. doi:10.1016/j.actbio.2014.07.027

65. Hoppstadter J, Seif M, Dembek A, Cavelius C, Huwer H, Kraegeloh $A$, Kiemer AK (2015). M2 polarization enhances silica nanoparticle uptake by macrophages. Front Pharmacol 6: 55. doi:10.3389/fphar.2015.00055
66. Tripathi K, Hussein UK, Anupalli R, Barnett R, Bachaboina L, Scalici J, Rocconi RP, Owen LB, Piazza GA, Palle K (2015). Allyl isothiocyanate induces replication-associated DNA damage response in NSCLC cells and sensitizes to ionizing radiation. Oncotarget 6: 5237-5252. doi:10.18632/oncotarget.3026

67. Niyazi M, Niyazi I, Belka C (2007). Counting colonies of clonogenic assays by using densitometric software. Radiat Oncol 2: 4. doi:10.1186/1748-717X-2-4

68. El-Maarri O (2004). SIRPH analysis: SNuPE with IP-RP-HPLC for quantitative measurements of DNA methylation at specific CpG sites. Methods Mol Biol 287: 195-205. doi:10.1385/1-59259-828-5:195

69. Gries J, Schumacher D, Arand J, Lutsik P, Markelova MR, Fichtner I, Walter J, Sers C, Tierling S (2013). Bi-PROF: bisulfite profiling of target regions using 454 GS FLX Titanium technology. Epigenetics 8: 765-771. doi:10.4161/epi.25242

70. Gabory A, Jammes H, Dandolo L (2010). The $H 19$ locus: Role of an imprinted non-coding RNA in growth and development. Bioessays 32 473. doi: $10.1002 /$ bies. 200900170

71. Kessler SM, Laggai S, Barghash A, Helms V, Kiemer AK (2014). Lipid metabolism signatures in NASH-associated HCC.--letter. Cancer Res 74: 2903-2904. doi:10.1158/0008-5472.CAN-13-2852

72. Kessler SM, Laggai S, Barghash A, Schultheiss CS, Lederer E, Artl M, Helms V, Haybaeck J, Kiemer AK (2015). IMP2/p62 induces genomic instability and an aggressive hepatocellular carcinoma phenotype. Cell Death Dis 6: e1894. doi:10.1038/cddis.2015.241

73. Park EJ, Lee JH, Yu GY, He G, Ali SR, Holzer RG, Österreicher $\mathrm{CH}$ Takahashi H, Karin M (2010). Dietary and Genetic Obesity Promote Liver Inflammation and Tumorigenesis by Enhancing IL-6 and TNF Expression. Cell 140: 197. doi: 10.1016/j.cell.2009.12.052

74. Naugler WE, Sakurai T, Kim S, Maeda S, Kim K, Elsharkawy AM, Karin M (2007). Gender disparity in liver cancer due to sex differences in MyD88-dependent IL-6 production. Science 317: 121-124. doi:10.1126/science. 1140485

75. Bettermann K, Mehta AK, Hofer EM, Wohlrab C, Golob-Schwarzl N, Svendova V, Schimek MG, Stumptner C, Thuringer A, Speicher MR, Lackner C, Zatloukal K, Denk H, Haybaeck J (2016). Keratin 18deficiency results in steatohepatitis and liver tumors in old mice: $A$ model of steatohepatitis-associated liver carcinogenesis. Oncotarget 7: 73309-73322. doi:10.18632/oncotarget.12325 